\title{
Novas demandas para as empresas de projeto de edifícios
}

\author{
New demands for building design firms
}

\author{
Nathália de Paula \\ Mônica Emiko Uechi \\ Silvio Burrattino Melhado
}

\section{Resumo \\ D}

esempenho, sustentabilidade ambiental de edifícios e BIM (Building

Information Modeling) são assuntos em evidência no subsetor

Edificações. A proposta deste artigo é analisar as características e o posicionamento de um grupo de sete empresas de projeto de edifícios da cidade de São Paulo, participantes de um programa dedicado ao

desenvolvimento gerencial de empresas de projeto, diante das novas demandas de desempenho, sustentabilidade ambiental e BIM, em sua interação com o mercado e clientes. O trabalho de pesquisa foi realizado em duas fases. A Fase 1 teve como objetivo verificar se as demandas estavam sendo consideradas pelas empresas, e intervir para evidenciar a importância de considerá-las estrategicamente, na busca de sua preparação para atender ao mercado. $O$ método de pesquisa utilizado nessa fase foi a pesquisa-ação. A Fase 2 de pesquisa consistiu na aplicação de um questionário, via correio eletrônico, para realizar uma verificação pós-intervenção dos pesquisadores sobre o posicionamento das empresas em relação a essas demandas. Apesar de reconhecer os pontos a trabalhar referentes às demandas, parte das empresas insiste em uma postura passiva diante delas. Recomenda-se que todas as empresas trabalhem seu planejamento estratégico e definam sua atuação, considerando seus pontos fortes e fracos, ameaças e oportunidades. Recomenda-se ainda que as empresas analisem se estão preparadas para atender às demandas e verifiquem a necessidade de alteração de seus processos, capacitação, treinamento interno e equipamentos, além de parcerias com os clientes.

Palavras-chave: Normas de desempenho. Sustentabilidade ambiental. Modelagem da informação da construção. Gestão. Empresas de projeto.

\begin{abstract}
Performance, environmental sustainability of buildings and BIM (Building Information Modeling) are topics in evidence in the Buildings subsector. Our aim is to analyze the characteristics and positioning of a group of seven building design firms in São Paulo city, participating in a management development program for design firms, regarding the new demands for performance, environmental sustainability and BIM, in their interaction with the market and clients. The research was conducted in two phases. Phase 1 aimed to verify if the demands were being considered by firms and to act in order to highlight the importance of considering them strategically in their preparation to meet the market. The research method used in this phase was the action research. Phase 2 consisted in the application of a questionnaire via webmail to carry out a post intervention analysis by researchers about the firms positioning in relation to these demands. Despite the recognizing the work points related to the demands, some firms persist in a passive behavior regarding them. We recommended that firms work their strategic planning and define their core business, considering their strengths and weaknesses, threats and opportunities. Also, it is recommended that firms assess whether they are prepared to meet the demands and verify the need of change in their processes, staff qualification, internal training and equipment, as well as partnership with clients.
\end{abstract}

Silvio Burrattino Melhado Universidade de São Paulo

Recebido em 15/04/13 São Paulo - SP - Brasil Aceito em 17/09/13

versidade de São Paulo

Mônica Emiko Uechi Universidade de São Paulo São Paulo - SP - Brasil

Keywords: Performance standards. En

Keywords: Performance standards. Envir
modelling. Management. Design firms. 


\section{Introdução}

Desempenho, sustentabilidade ambiental de edifícios e BIM (Building Information Modeling) são assuntos em evidência no subsetor Edificações. A norma NBR 15575 Edificações Habitacionais Desempenho (ABNT, 2013) entrou em vigor recentemente no Brasil; edifícios com exigências sustentáveis são cada vez mais frequentes no mercado; e o BIM tem sido apontado como a grande solução aos agentes, que permite o trabalho integrado, a fácil identificação de incompatibilidades entre as disciplinas de projeto, a simulação ambiental do edifício, a extração de quantitativos, etc.

As entidades de classe estão reconhecendo a importância desses assuntos. Recentemente, os Manuais de Escopo para Contratação de Projetos e Serviços para a Indústria Imobiliária (SECOVI, 2013) foram revisados e passaram a mencionar esses aspectos. O RIBA (Royal Institute of British Architects) realizou revisões em seu Plan of Work de 2007, incorporando sustentabilidade em 2011 e BIM em 2012. Em 2013, o Instituto reformulou o plano e reviu seus estágios de trabalho. O Plan of Work é um documento de referência para os agentes envolvidos nos processos de concepção, projeto, construção do edifício e pós-ocupação (ROYAL..., 2013).

A tendência atual é a de que os projetos de edifícios sejam concebidos com enfoque em desempenho, o que significa considerar os requisitos de desempenho desde a fase de concepção, nas definições das exigências do programa de necessidades. Cada vez mais a prática de projetar com enfoque em desempenho deve ser incorporada ao processo de projeto, principalmente em razão das crescentes preocupações com durabilidade e sustentabilidade (OLIVEIRA; MITIDIERI FILHO, 2012).

No que se refere ao desenvolvimento de projetos, os agentes - projetistas, consultores, construtores e fornecedores - terão de modificar suas práticas atuais (OLIVEIRA; MITIDIERI FILHO, 2012). De acordo com Trinius e Sjöström (2005), os projetistas deverão garantir que o projeto, considerando os produtos e os componentes escolhidos, atenda aos requisitos de desempenho, diferentemente de quando se trabalha com requisitos prescritivos.

A Câmara Brasileira da Indústria da Construção lançou um guia orientativo para atendimento à norma de desempenho (ABNT, 2013), que contém um resumo das incumbências dos projetistas, referentes às ações que visam atingir e manter os níveis de desempenho dos edifícios pretendidos.
Segundo o CBIC (CÂMARA..., 2013), os projetistas devem estabelecer e indicar nos respectivos memoriais e desenhos a vida útil de projeto (VUP) de cada sistema que compõe a obra, especificando materiais, produtos e processos que isoladamente ou em conjunto venham a atender ao desempenho requerido. Para que a VUP possa ser atingida, o projetista deve recorrer às boas práticas de projeto, às disposições de normas técnicas prescritivas, ao desempenho demonstrado pelos fabricantes dos produtos contemplados no projeto e a outros recursos do estado da arte mais atual (CÂMARA..., 2013).

Conforme o CBIC (CÂMARA..., 2013), quando as normas específicas de produtos não caracterizarem desempenho, quando não existirem normas específicas ou quando o fabricante não tiver publicado o desempenho de seu produto, compete ao projetista solicitar informações ao fabricante para balizar as decisões de especificação. Quando valores de VUP maiores que os mínimos estabelecidos na norma forem considerados, esses valores deverão constar dos projetos e/ou memorial de cálculo (CÂMARA..., 2013).

Neste artigo, entende-se que a gestão das empresas de projeto pode auxiliar em sua preparação para atender à norma de desempenho, pois essa preparação envolve seus diversos processos:

(a) planejamento estratégico, considerando que a discussão da norma não é nova e deveria estar inserida no planejamento;

(b) gestão de pessoas, pela necessidade de capacitação; e

(c) gestão financeira, pelo investimento em capacitação, softwares e equipamentos, entre outros.

Assim como desempenho, a sustentabilidade ambiental de edifícios também se configura em uma demanda de mercado. Como resultado principalmente de processos de certificação ambiental, novos requisitos passam a compor os parâmetros técnicos exigíveis de cada disciplina de projeto, inclusive pela presença de novos agentes no processo de projeto, tais como os consultores ambientais e os especialistas em diversas áreas (MELHADO, 2012; DE PAULA; MELHADO, 2012).

A produção de edifícios sustentáveis requer:

(a) a introdução de novos métodos e ferramentas para a avaliação de edifícios, com abordagem do edifício como um todo e melhor entendimento sobre a interação de componentes e seu desempenho geral;

138 Paula, N. de; Uechi, M.; Melhado, S. 
(b) o uso de novos materiais e novas soluções técnicas;

(c) a integração de novos agentes;

(d) melhor arranjo e interação de incorporadores, projetistas e construtoras;

(e) novas competências e entendimento sobre construção sustentável por agentes envolvidos; e

(f) novos procedimentos, tais como caminhos para a certificação ambiental e controle da qualidade (REKOLA; MÄKELÄINEN; HÄKKINEN, 2012).

Para Salgado, Chatelet e Fernandez (2012), mudanças na organização e gestão do processo de projeto são necessárias a fim de atender aos requisitos de desempenho ambiental do edifício, e sua melhoria depende do estabelecimento de um sistema de gestão que auxilie os profissionais a lidar com esses requisitos. Segundo os mesmos autores, as condicionantes da produção de edifícios que considerem os princípios da qualidade ambiental podem ser divididas em técnicas e organizacionais. As técnicas se relacionam à qualidade ambiental do produto edifício em todo seu ciclo de vida, traduzida pelas soluções de projeto. Já as organizacionais se relacionam às práticas adotadas no dia a dia das empresas, que precisam ser analisadas e adaptadas, para que os profissionais possam atender positivamente às demandas do projeto integrado - fundamental para a construção sustentável.

Somando-se ao desempenho e à sustentabilidade ambiental de edifícios, o conceito BIM é considerado uma demanda de mercado. Segundo Eastman et al. (2008, p. 13), BIM é "[...] uma tecnologia de modelagem e um grupo associado de processos para produção, comunicação e análise do modelo de construção [...]".

O compartilhamento de informações de projeto por meio de um modelo digital traz restrições adicionais para cada agente participante da equipe de projeto. Para isso, os projetistas devem rever sua organização interna para trabalhar sobre uma mesma estrutura de dados do projeto, de uma forma transversal, utilizando a mesma metodologia e trabalhando com elementos compartilhados: elementos topográficos, de arquitetura, especificações de materiais, dados de custos, elementos estruturais, projeto do canteiro de obras, etc. (FERRIES, 2009). A modelagem do projeto é desenvolvida progressivamente, permitindo visualizar o avanço ou alterações de projeto (FERRIES, 2009).

Succar (2009) define os estágios de evolução da implementação do BIM e os pontos a serem trabalhados para que a evolução ocorra de um estágio para o outro. O volume e a complexidade das mudanças identificadas nos estágios BIM, tanto organizacionais como industriais, são transformacionais e não podem ser implementadas sem uma evolução incremental (SUCCAR, 2009). Analisando os pontos a serem trabalhados, apresentados pelo autor, observa-se que muitos deles possuem relação com a gestão das empresas, envolvem seus diversos processos: gestão financeira, pelo investimento em software e hardware; gestão de pessoas, pela capacitação; gestão do processo de projeto, pelas mudanças nas práticas de projeto; planejamento estratégico, pela necessidade de acompanhamento da evolução do BIM, entre outros.

Muitos autores (OLATUNJI, 2011; KHOSROWSHAHI; ARAYICI, 2012; GU; LONDON, 2010; ARAYICI et al., 2011) discorrem sobre os aspectos não técnicos e técnicos relacionados à implementação do BIM: definição de objetivos, custos, cultura organizacional, gestão da informação, processo de projeto, práticas de trabalho, software, hardware, treinamentos, projeto piloto, gestão do conhecimento, entre outros. Entretanto, esses autores não fazem uma clara relação desses aspectos com a gestão das empresas.

$\mathrm{O}$ potencial do relacionamento entre BIM e sustentabilidade ambiental deve ser destacado (PARK et al. 2012; AZHAR et al., 2011). Conforme Bynum, Issa e Olbina (2013), devido ao aumento anual da demanda pela adoção do conceito BIM e incorporação dos requisitos de sustentabilidade, o desenvolvimento de plataformas mais sofisticadas e robustas se mostra necessário. Medidas sustentáveis devem ser aprimoradas a fim de melhorar os resultados dos edifícios em relação a suas metas ambientais. O BIM deve evoluir para integrar as análises ambientais e melhorar a interoperabilidade. O avanço da tecnologia auxiliará a sustentabilidade e o BIM no estabelecimento de padrões de excelência no futuro. No entanto, o setor e os empreendedores devem estar dispostos a implementar essas ferramentas de desempenho em suas práticas. Além disso, as partes interessadas devem estar dispostas a cooperar uma com a outra, de modo a empregar um esforço colaborativo na produção de edifícios sustentáveis.

Segundo Melhado (2012, p. 105), 


\begin{abstract}
em seu 'mundo único', os projetistas muitas vezes se mostram fortemente reativos às necessidades de melhoria da gestão. Até certo ponto, mas não abertamente, esses profissionais questionam a real necessidade de se fazer gestão, mesmo se essa necessidade for perceptível em sua própria prática diária. Outro perfil típico do profissional de projeto pode ser denominado gestor 'autodidata', representado pela adoção de métodos por vezes ineficientes e controles muito burocráticos.
\end{abstract}

As empresas de projeto possuem uma série de deficiências em suas práticas de gestão. Souza (2009) aponta as seguintes:

(a) inexistência de visão e planejamento estratégico;

(b) produtos e serviços não formalizados e divulgados, dentro e fora da empresa;

(c) centralização de decisões e de responsabilidades;

(d) inexistência de um fluxo de trabalho organizado e ferramentas para controle, análise crítica e retroalimentação do processo de projeto;

(e) inexistência de um fluxo de informações, ferramentas para controle e retroalimentação dos processos gerenciais;

(f) desorganização das finanças (controle de despesas e receitas por projeto, de despesas gerais da empresa, planos de investimento, etc.);

(g) inexistência de planos de ação e controles voltados para a gestão de pessoas; e

(h) desorganização do processo comercial.

Internacionalmente, o trabalho de Zhao et al. (2012) - que apresenta exemplos de estratégias para as empresas de projeto estrangeiras melhorarem sua competitividade na China - deve ser mencionado. Esses autores utilizaram o Modelo Diamante de Porter e a análise SWOT ${ }^{1}$ (Strengths, Weaknesses, Opportunities e Threats) para definir as estratégias. O Modelo Diamante de Porter é uma técnica para identificar os fatores que a empresa deve considerar na operação do negócio e as interações entre esses fatores com sua estrutura organizacional, a concorrência externa e as decisões estratégias (ZHAO et al., 2012). A análise SWOT contempla as análises ambiental, ou externa, e interna à empresa. A investigação do ambiente externo resulta em uma visão geral das oportunidades e ameaças para a empresa, e a

\footnotetext{
${ }^{1}$ Sobre a aplicação da análise SWOT em uma empresa de projeto
} brasileira, consultar Novaski et al. (2012). investigação do ambiente interno resulta em uma visão geral de seus pontos fortes e fracos (HOUBE; LENIE; VANHOOF, 1999). As técnicas utilizadas se mostram interessantes para trabalhar demandas de mercado, porém os referidos autores citam a estrutura das empresas, mas não fazem a relação clara entre gestão e demandas.

É nesse contexto que o presente trabalho se insere: considerando a estrutura gerencial das empresas de projeto de edifícios, questiona como elas estão se posicionando diante das novas demandas de mercado. As contribuições do artigo são:

(a) a descrição do posicionamento e a percepção de um grupo de empresas em relação às demandas;

(b) a identificação de fatores que influenciam o posicionamento dessas empresas; e

(c) a análise de sua influência.

Desse modo, a proposta deste artigo é analisar as características e o posicionamento de um grupo de sete empresas de projeto de edifícios da cidade de São Paulo, participantes de um programa dedicado ao desenvolvimento gerencial de empresas de projeto, ante as novas demandas de desempenho, sustentabilidade ambiental de edifícios e BIM, em sua interação com o mercado e clientes.

O foco deste trabalho não é a implementação de modelos de gestão. Porém, considerações gerais sobre esse assunto e a estrutura de gestão das empresas de projeto são realizadas no âmbito do programa de desenvolvimento gerencial, devido à relação entre a gestão e as demandas. As empresas estudadas atuam em um contexto específico, que é o da cidade de São Paulo. Entretanto, esse artigo se configura como uma referência para a investigação de como as empresas de outras regiões estão se posicionando diante dessas demandas.

\section{Metodologia de pesquisa}

$\mathrm{O}$ trabalho de pesquisa foi realizado em duas fases, conforme apresenta a Figura 1, as quais são detalhadas a seguir. A Fase 1 teve como objetivo verificar se as demandas de desempenho, sustentabilidade ambiental e modelagem da informação da construção estavam sendo consideradas pelas empresas, e intervir para evidenciar a importância de considerá-las estrategicamente, na busca de sua preparação para atender ao mercado. O objetivo da Fase 2 de pesquisa foi realizar uma verificação pósintervenção dos pesquisadores sobre o posicionamento das empresas em relação a essas demandas. 


\section{Fase 1 da pesquisa - trabalho referente às demandas de mercado com as empresas de projeto}

A Fase 1 da pesquisa ocorreu no contexto da quinta edição do Programa de Desenvolvimento Gerencial para Empresas de Projeto (PDGEP), conforme a Figura 1.

\section{Programa de desenvolvimento gerencial para empresas de projeto}

O PDGEP, também conhecido como Soluções para Empresas de Projeto, é uma iniciativa da Linha de Pesquisa em Gestão de Projetos, do Departamento de Engenharia de Construção Civil da Escola Politécnica da USP. O programa surgiu da constatação de que os egressos das faculdades de engenharia e arquitetura que criam empresas ou mesmo empresários com anos de atuação têm dificuldades para administrá-las.

Iniciou-se esse programa em 2006, com o objetivo de promover o desenvolvimento gerencial das empresas de projeto, por meio da implementação de um modelo de gestão. Foram realizadas cinco edições, em 2006, 2007, 2008, 2010 e 2011. O fechamento de cada grupo de trabalho ocorreu por meio de um evento, cujos objetivos foram apresentar os resultados de desenvolvimento gerencial das empresas participantes e possibilitar a discussão de assuntos de interesse comum para as empresas de projeto do setor da construção civil.

O modelo trabalhado no PDGEP é o modelo de gestão para pequenas empresas de projeto de edifícios proposto por Oliveira (2005), composto dos seguintes módulos: estrutura organizacional, planejamento estratégico, planejamento e controle do processo de projeto, gestão financeira, gestão comercial e marketing, sistema de informação, gestão de pessoas e serviços agregados ao projeto e avaliação de desempenho (Figura 2).

Cada um dos módulos de gestão é descrito no Quadro 1, por meio do detalhamento de seus objetivos no contexto da implementação do modelo em empresas de projeto.

\section{Sistemática de trabalho empregada no PDGEP 5}

O método de pesquisa utilizado no PDGEP foi a pesquisa-ação. Thiollent (2004, p. 14) define pesquisa-ação como

[...] um tipo de pesquisa social com base empírica que é concebida e realizada em estreita associação com uma ação ou com a resolução de um problema coletivo e no qual os pesquisadores e os participantes representativos da situação ou do problema estão envolvidos de modo cooperativo ou participativo [...].

Figura 1 - Metodologia de pesquisa

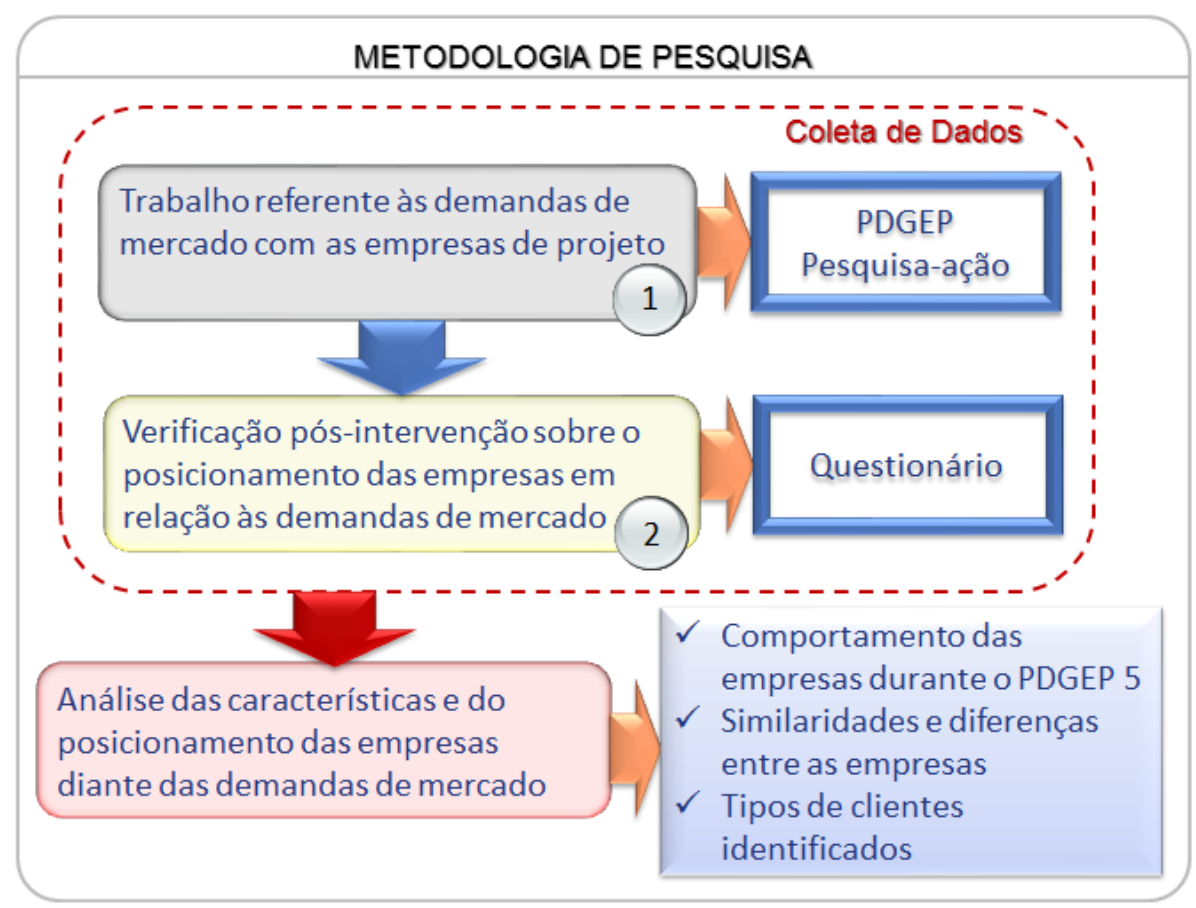


Figura 2 - Modelo de gestão para pequenas empresas de projeto

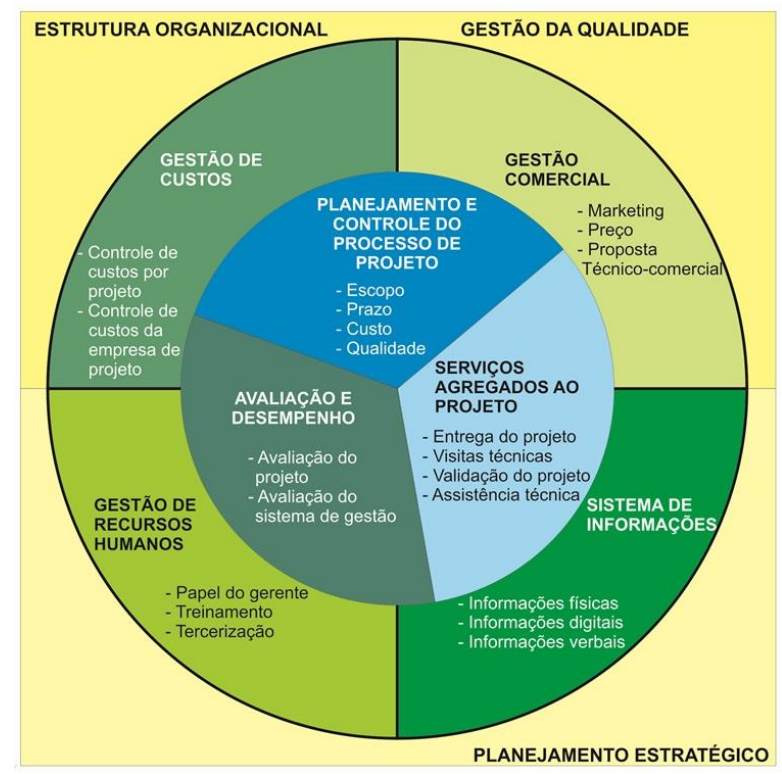

Fonte: adaptada de Oliveira (2005).

Quadro 1 - Descrição dos módulos de gestão

\begin{tabular}{|c|c|}
\hline $\begin{array}{l}\text { Módulo de } \\
\text { Gestão }\end{array}$ & Objetivos no contexto da implementação do modelo \\
\hline $\begin{array}{l}\text { Estrutura } \\
\text { organizacional }\end{array}$ & $\begin{array}{l}\text { Deve-se analisar como a estrutura da empresa permite a execução de suas estratégias e a } \\
\text { realização de seu trabalho. Além disso, deve-se considerar como a estrutura se harmoniza } \\
\text { com os indivíduos que ali trabalham e qual é o impacto sobre suas atividades. }\end{array}$ \\
\hline $\begin{array}{l}\text { Planejamento } \\
\text { estratégico }\end{array}$ & $\begin{array}{l}\text { Permite conhecer e melhor utilizar os pontos fortes da empresa; conhecer, eliminar ou } \\
\text { adequar seus pontos fracos; conhecer e aproveitar as oportunidades externas, assim como } \\
\text { evitar as ameaças; criar uma agenda para objetivos e metas da empresa. }\end{array}$ \\
\hline $\begin{array}{l}\text { Planejamento e } \\
\text { controle do } \\
\text { processo de } \\
\text { projeto }\end{array}$ & $\begin{array}{l}\text { A elaboração de instrumentos para planejamento e controle do processo de projeto traz } \\
\text { consideráveis benefícios ao processo de avaliação final do projeto, tanto em relação aos } \\
\text { aspectos técnicos quanto com relação aos aspectos de gestão. Os dados advindos desses } \\
\text { instrumentos possibilitam o estabelecimento de diretrizes para o aprimoramento dos novos } \\
\text { projetos, por meio da comparação entre as atividades previstas e as realmente realizadas. }\end{array}$ \\
\hline $\begin{array}{l}\text { Gestão } \\
\text { financeira }\end{array}$ & $\begin{array}{l}\text { Instrumentos simplificados para organização e controle das receitas, dos custos fixos e dos } \\
\text { custos diretos da pequena empresa de projetos de edifícios devem ser desenvolvidos. }\end{array}$ \\
\hline $\begin{array}{l}\text { Gestão } \\
\text { comercial e } \\
\text { marketing }\end{array}$ & $\begin{array}{l}\text { Estratégias e ferramentas de marketing devem ser definidas com o objetivo de fazer com } \\
\text { que o cliente perceba que o serviço "projeto" é parte indissociável do produto edifício, de } \\
\text { modo a criar a sensação de necessidade desse serviço. Além disso, um método para } \\
\text { precificação dos projetos deve ser estabelecido, e as propostas técnico-comerciais devem } \\
\text { ser elaboradas. }\end{array}$ \\
\hline $\begin{array}{l}\text { Sistema de } \\
\text { informação }\end{array}$ & $\begin{array}{l}\text { Mecanismos simples e consistentes para emissão, recebimento e armazenagem das } \\
\text { informações necessárias para o processo de projeto e para a gestão da empresa de projeto } \\
\text { devem ser criados, de modo a facilitar a disponibilidade e a quantidade da informação no } \\
\text { momento certo. }\end{array}$ \\
\hline $\begin{array}{l}\text { Gestão de } \\
\text { pessoas }\end{array}$ & $\begin{array}{l}\text { Procedimentos simples e básicos para a contratação de colaboradores, educação } \\
\text { continuada e treinamento devem ser propostos, bem como para a organização das } \\
\text { terceirizações, com enfoque para o aperfeiçoamento tecnológico dos profissionais, } \\
\text { melhoria do clima organizacional e garantia de melhor qualidade dos projetos realizados } \\
\text { pela empresa. }\end{array}$ \\
\hline $\begin{array}{l}\text { Serviços } \\
\text { agregados ao } \\
\text { projeto }\end{array}$ & $\begin{array}{l}\text { Práticas devem ser estabelecidas com o objetivo de criar uma linha direta de comunicação } \\
\text { com o cliente e usuários do projeto (contratante, obra e usuário da edificação), de modo a } \\
\text { aperfeiçoar continuamente o processo de projeto. }\end{array}$ \\
\hline $\begin{array}{l}\text { Avaliação de } \\
\text { desempenho }\end{array}$ & $\begin{array}{l}\text { Uma sistemática para avaliação do desempenho dos projetos desenvolvidos pela empresa e } \\
\text { avaliação do desempenho de seu sistema de gestão devem ser propostas. }\end{array}$ \\
\hline
\end{tabular}

142 Paula, N. de; Uechi, M.; Melhado, S. 
O método foi escolhido em função das peculiaridades do programa no qual a pesquisa estava inserida, que proporcionava uma ampla interação entre os pesquisadores e as empresas envolvidas voluntariamente - os pesquisadores tiveram a oportunidade de se aproximar da realidade dos pesquisados. Outro aspecto relevante na escolha do método relaciona-se ao fato de que o objeto de investigação não é constituído somente pelas empresas, mas pelo contexto em que estão inseridas e pelos problemas de diferentes naturezas encontrados.

Como já mencionado, a Fase 1 da pesquisa ocorreu no contexto da quinta edição do PDGEP, ou "Soluções 5", a qual teve início em maio de 2011 e finalização em novembro de 2012, com o evento "V Seminário sobre Soluções de Gestão para Empresas de Projeto: A Gestão de Empresas em Tempos de Crescimento". A Figura 3 apresenta a sistemática de trabalho utilizada no programa.

A rotina do "Soluções 5" foi composta de reuniões mensais com as empresas de projeto. Durante as reuniões, foram:

(a) realizadas apresentações referentes aos módulos de gestão, promovendo a discussão sobre os conceitos implícitos no modelo de Oliveira (2005) (item $i$ da Figura 3);

(b) realizadas dinâmicas em grupo a fim de estimular a troca de experiências entre as empresas nas reuniões (item $i$ da Figura 3);

(c) realizadas palestras com especialistas do mercado sobre as demandas atuais - desempenho de edifícios, sustentabilidade ambiental de edifícios e BIM (item ii da Figura 3); (d) solicitados diagnósticos para verificar o estágio dos módulos de gestão nas empresas e a consideração das demandas de mercado. A partir desses diagnósticos, as necessidades gerenciais foram levantadas (item iii da Figura 3);

(e) solicitadas tarefas, baseadas em Souza (2009), para promover a aplicação dos conceitos de gestão e o trabalho com as demandas, ambos discutidos nas reuniões (item $i v$ da Figura 3); e

(f) apresentadas as lições aprendidas pelas empresas, possibilitando a compreensão de suas dificuldades e benefícios referentes aos módulos de gestão (item $v$ da Figura 3).

Os diagnósticos e as tarefas foram desenvolvidos no dia a dia de cada empresa, resultando em alterações e desenvolvimento de sua estrutura de gestão - as tarefas foram apresentadas pelas empresas nas reuniões mensais. As empresas contaram com o auxílio de um colaborador dedicado à implementação do modelo de gestão. Esse colaborador atuava tanto na empresa como no grupo de pesquisa de gestão e era responsável por elaborar relatórios sobre o andamento do trabalho.

Adicionalmente, foram realizadas visitas às empresas (item vi da Figura 3) pela coordenadora do PDGEP, coautora deste artigo, e uma aluna de Iniciação Científica. Tais visitas consistiram em reuniões com o objetivo de analisar a evolução das empresas em relação aos módulos trabalhados, além de constatar problemas de gestão, de modo a buscar maneiras de resolvê-los, resultando em um plano de ação para cada empresa.

\section{Figura 3 - Sistemática de trabalho do PDGEP 5}

FECHAMENTO: Evento SOLUÇÕES PARA EMPRESAS DE PROJETO

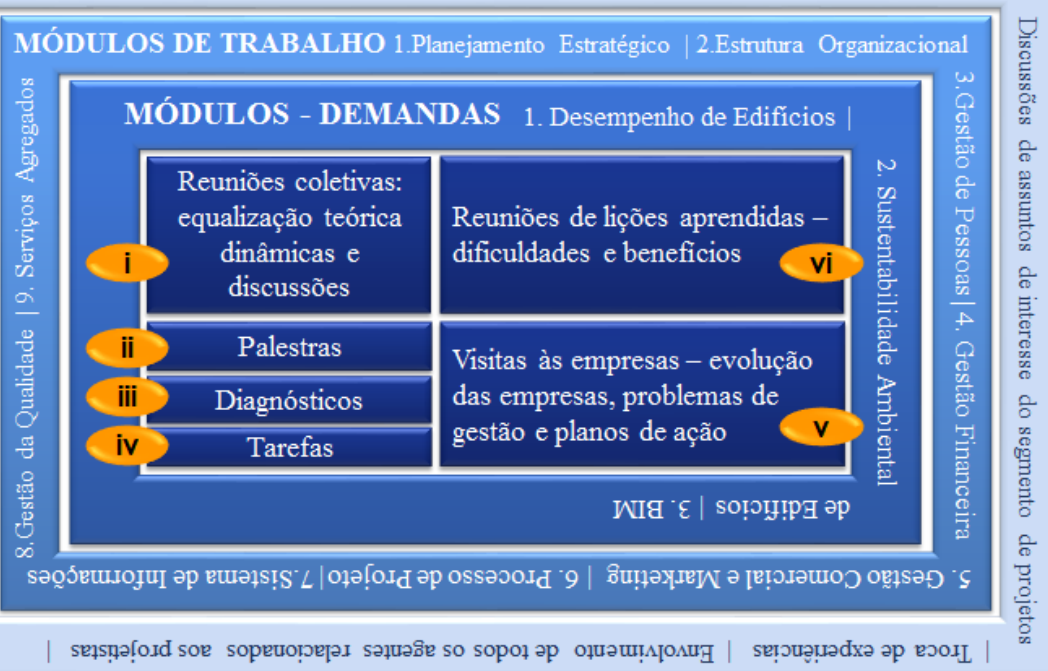


Dois dos autores deste artigo atuaram como coordenadores do programa. Um, com participação geral, realizou as apresentações dos módulos de gestão e orientou as empresas durante as reuniões, contribuindo com sua experiência; outro, com participação em todos os assuntos do programa, desde a organização das reuniões, comunicação com as empresas, preparação de todo o material utilizado, orientação dos colaboradores, visita às empresas até a gestão dos arquivos em um ambiente colaborativo. Um dos autores atuou como colaborador em uma das empresas e no grupo de pesquisa, auxiliando os coordenadores e os outros colaboradores.

O método de pesquisa se mostrou consistente, já que está construído em um ciclo que inclui diagnóstico (o que existe na empresa), trabalho do módulo ou demanda e lições aprendidas. Diversas são as fontes de dados:

(a) diagnósticos, um por módulo, total de 12;

(b) tarefas, uma por módulo, total de 12;

(c) visitas, duas por empresa, realizadas no meio e no final do programa, total de 14 ;

(d) relatórios dos colaboradores de gestão, um por módulo, total de 12; e

(e) lições aprendidas, apresentadas no meio e no final do programa, total de 14 apresentações.

Entre reuniões com as empresas e os colaboradores, visitas e preparação de material, $150 \mathrm{~h}$ de trabalho foram investidas.

\section{Fase 2 da pesquisa - Posicionamento das empresas de projeto em relação às demandas de mercado}

A Fase 2 de pesquisa consistiu em aplicação de um questionário, via correio eletrônico, para realizar uma verificação pós-intervenção dos pesquisadores sobre o posicionamento das empresas em relação às demandas de mercado (Figura 1).

Para compor o questionário aplicado após a pesquisa-ação, em março de 2013, questões abertas sobre as demandas, contidas no material da Fase 1, foram selecionadas em alinhamento com o objetivo do artigo, ou seja, buscando entender a postura das empresas diante das demandas. As questões podem ser verificadas nos Quadros 4, 5, 6 e 7; foi aplicado um questionário por empresa, que foi respondido por seu titular ou diretor.

\section{Análise de dados}

A pesquisa-ação, Fase 1 da pesquisa, teve duração de um ano e meio, ou seja, foi um trabalho de longo período que possibilitou conhecer e observar as empresas profundamente. Por estarem acostumados com os questionários do PDGEP, terem simpatia pelo programa e conhecerem os pesquisadores, os titulares e diretores responderam ao questionário, Fase 2 da pesquisa, com afinco e rapidez, o que permitiu uma boa coleta de dados.

A análise das características e do posicionamento das empresas ante as demandas de mercado foi realizada com base em múltiplas evidências, considerando: o comportamento das empresas durante o PDGEP 5; as similaridades $\mathrm{e}$ as diferenças entre as empresas, percebidas pelos pesquisadores; os tipos de clientes atendidos pelas empresas, os quais demandam ou não desempenho, sustentabilidade ambiental e BIM (Figura 1). Essa análise permitiu identificar os fatores influentes no posicionamento adotado pelas empresas:

(a) tipo de cliente atendido, se ele demanda desempenho, sustentabilidade ambiental e/ou BIM ou não;

(b) características, se a empresa é inovadora e dinâmica (promove mudanças e procura se atualizar por observação do mercado e/ou motivação própria), ou conversadora e lenta (evita mudanças e atualizações, esperando forças externas para verificar a possibilidade de ocorrerem) diante das demandas;

(c) percepção e/ou entendimento sobre as demandas, se a empresa observa o mercado, percebe tendências e as entende;

(d) posicionamento em face das demandas, se a empresa traça estratégias e/ou promove ações para considerar as demandas em seus projetos;

(e) especialidade de projeto desenvolvida, se a empresa tem um trabalho abrangente (arquitetura) ou focado (esquadrias, ar condicionado, etc.); e

(f) estrutura de gestão, se permite que a empresa trabalhe as demandas atuais.

O Quadro 8 apresenta a análise da influência desses fatores no posicionamento das empresas.

\section{Novas demandas para as empresas de projeto de edifícios}

\section{Características das empresas}

Sete empresas de projeto da cidade de São Paulo foram estudadas, as quais estão caracterizadas no Quadro 2. Três das empresas (empresas A, B e C) apresentam uma posição relevante no mercado de projetos, o que se comprova pelo grande número

144 Paula, N. de; Uechi, M.; Melhado, S. 
de projetos realizados, características dos clientes, que incluem grandes empresas, e também pelos aspectos inovadores dos projetos das edificações em que estão envolvidos. As empresas trabalham com diferentes especialidades de projeto, o que não impediu a realização de análises e comparações, uma vez que o foco do artigo está em suas estruturas de gestão e em como lidam com as demandas de desempenho, sustentabilidade e BIM.

\section{Participação das empresas no PDGEP 5}

\section{Considerações gerais sobre a implementação do modelo de Oliveira (2005)}

O grupo de empresas do PDGEP 5 apresentou diversidade em relação a seus nichos de mercado, especialidades técnicas e tempo de atuação no mercado (Quadro 2). Entretanto, apesar dessas diferenças, os problemas de gestão eram, em grande parte, os mesmos.

Ao início do programa, foram apresentados os módulos de planejamento estratégico e estrutura organizacional. Verificou-se que nenhuma das empresas possuía um planejamento estratégico formalizado e colocado em prática, então elas foram estimuladas a criá-lo. Do mesmo modo, foi ressaltada a importância de se formalizar a estrutura organizacional de cada empresa, atribuindo funções a seus respectivos cargos e explicitando os papéis de todos os colaboradores.

Todas as empresas apresentaram dificuldades em implementar melhorias de gestão em suas rotinas. Os titulares possuem dois papéis: o de projetista e o de gestor da empresa. Esses papéis não estavam muito claros para alguns participantes. Destacou-se a importância de gerir o escritório como uma empresa que possui diversos processos, muitas vezes com relação direta pouco perceptível à atividade principal do projetista, que é desenvolver projetos.

O segundo módulo, gestão de pessoas, foi aquele em que um maior número de ferramentas de gestão foi criado pelas empresas, manifestando a dificuldade nesse módulo e sua importância para os participantes. As ferramentas criadas se referem à seleção de pessoas, pesquisa de clima organizacional, avaliação de colaboradores, etc.

No que se refere ao módulo de gestão comercial e marketing, algumas empresas se mostraram satisfeitas com seu modo de divulgação, seja por meio de websites, portfólio ou revistas; e também com suas propostas técnico-comerciais, estudadas e remodeladas. Outras empresas estão trabalhando de forma a evoluir no que diz respeito a sua gestão comercial, com a criação de ferramentas e processos que as ajudarão a atrair mais clientes e atendê-los melhor em suas necessidades.

Em relação ao módulo de gestão financeira, percebeu-se grande preocupação com controle das horas despendidas ao desenvolvimento projeto, ou seja, com seu custo e a produtividade de seus colaboradores. A maioria das empresas não tem controle financeiro adequado, pois os orçamentos de seus projetos são feitos apenas com base no preço do mercado. As poucas que apresentam uma boa gestão financeira utilizam softwares específicos para essa finalidade.

\section{Quadro 2 - Características das empresas}

\begin{tabular}{|l|c|c|c|c|c|c|c|}
\hline $\begin{array}{l}\text { Empresa e } \\
\text { Informação }\end{array}$ & $A$ & $B$ & $C$ & $D$ & $E$ & $F$ & $G$ \\
\hline $\begin{array}{l}\text { Especialidade } \\
\text { de projeto }\end{array}$ & $\begin{array}{c}\text { Esquadrias } \\
\text { e fachadas } \\
\text { em } \\
\text { alumínio }\end{array}$ & $\begin{array}{c}\mathrm{Ar} \\
\text { condicionado, } \\
\text { ventilação e } \\
\text { refrigeração }\end{array}$ & $\begin{array}{c}\text { Instalações } \\
\text { prediais } \\
\text { (elétrica, } \\
\text { hidráulica e } \\
\text { automação) }\end{array}$ & $\begin{array}{c}\text { Arquitetura e } \\
\text { compatibilização }\end{array}$ & $\begin{array}{c}\text { Arquitetura } \\
\text { (ênfase em } \\
\text { interiores) }\end{array}$ & $\begin{array}{c}\text { Arquitetura, } \\
\text { design, jogos } \\
\text { e sinalização }\end{array}$ & $\begin{array}{c}\text { Arquitetura, } \\
\text { coordenação e } \\
\text { compatibili- } \\
\text { zação }\end{array}$ \\
\hline $\begin{array}{l}\text { Tempo de } \\
\text { Atuação (anos) }\end{array}$ & 8 & 48 & 41 & 4 & 5 meses & 5 & 25 \\
\hline $\begin{array}{l}\text { Segmento de } \\
\text { Atuação }\end{array}$ & $\mathrm{R} \mathrm{e} \mathrm{C}$ & $\mathrm{C}$ & $\mathrm{R} \mathrm{e} \mathrm{C}$ & $\mathrm{R} \mathrm{e} \mathrm{C}$ & $\mathrm{R} \mathrm{e} \mathrm{C}$ & $\mathrm{R} \mathrm{e} \mathrm{C}$ & $\mathrm{R} \mathrm{e} \mathrm{C}$ \\
\hline $\begin{array}{l}\text { Número de } \\
\text { Colaboradores }\end{array}$ & 7 & 33 & 43 & 6 & 6 & 12 & 10 \\
\hline $\begin{array}{l}\text { Máximo de } \\
\text { projetos } \\
\text { simultâneos }\end{array}$ & 12 & 90 & 36 & 10 & 15 & 16 & 15 \\
\hline
\end{tabular}

Nota: Legenda:

$\mathrm{R}=$ Residencial; $\mathrm{e}$

$\mathrm{C}=$ Comercial. 
Assim como gestão de pessoas, processo de projeto também foi um dos módulos com maior quantidade de ferramentas de gestão desenvolvidas, tais como manual e check-list de projeto. Isso indica maior atenção das empresas nesse módulo, principalmente pelo fato de ser o que mais influencia o cotidiano dos colaboradores e dos titulares das empresas.

O sistema de informações se mostrou um módulo crítico, pois, nas empresas de projeto, predomina a comunicação informal. Nesse módulo, muitas soluções simples, como um mural de recados, foram implementadas. Além disso, foi trabalhada a relação entre os módulos de gestão, reunindo as ferramentas criadas.

O último módulo trabalhado no programa foi gestão da qualidade. As empresas tomaram conhecimento sobre o Programa Setorial da Qualidade e Referencial Normativo para Qualificação de Empresas de Projeto (MELHADO; CAMBIAGHI, 2006).

A partir das dificuldades encontradas pelas empresas na implementação do modelo de gestão, é possível realizar considerações sobre suas estruturas gerenciais.

A empresa A é a mais evoluída em termos de gestão, isso devido ao trabalho de alguns anos em busca da melhoria de seus processos. A partir da identificação de suas necessidades, a empresa desenvolveu um sistema de informações gerenciais (SIG) - o processo de desenvolvimento lhe proporcionou amadurecimento organizacional. A empresa possui algumas dificuldades, tais como aliar a capacidade produtiva com a demanda do mercado; treinamento de pessoal; valorizar o conceito do projeto de esquadrias; e disponibilizar tempo para cuidar da gestão da empresa.

A empresa B possui muitos anos de atuação no mercado, e sua estrutura é bastante conservadora. Há dificuldade para:

(a) abandonar a visão predominantemente técnica ao conduzir seu negócio, de modo a desenvolver uma visão mais empreendedora e abrangente;

(b) identificar as estratégias e as ferramentas mais adequadas para a empresa em cada processo;

(c) identificar a melhor abordagem quanto ao treinamento, acompanhamento e à motivação das pessoas; $\mathrm{e}$

(d) lidar com a alta rotatividade na empresa.

Apesar de, há muitos anos, atuar no mercado, tendendo ao conservadorismo, um dos diretores da empresa $\mathrm{C}$ entende a importância da estruturação e melhoria da gestão e possui uma visão empreendedora. As dificuldades mencionadas por ele são:

(a) inclusão da gestão na rotina da empresa;

(b) compatibilização do cronograma de treinamento com a rotina de projetos do colaborador;

(c) levantamento dos custos reais de projetos;

(d) especialização de um colaborador em determinado assunto, sem haver outro com a mesma capacitação;

(e) demanda do mercado por novo modelo de processo de projeto (antecipação dos detalhamentos para levantamento de custos);

(f) comunicação e conferência das informações que surgem no decorrer do projeto; e

(g) dificuldade no atendimento aos requisitos de projeto, devido à deficiência no fluxo e no tratamento das informações.

A empresa D possui entendimento sobre a importância da gestão, porém há dificuldade por parte dos titulares em conciliar seus papéis de gestores e projetistas. Algumas dificuldades levantadas por eles são:

(a) inclusão da gestão na rotina da empresa;

(b) falta de experiência na área de gestão;

(c) falta de motivação para a realização de atividades de gestão;

(d) conscientização dos gerentes de projeto de que devem cadastrar seus gastos e custos;

(e) definição de responsável em cada etapa da produção do projeto;

(f) informações dispersas, apesar de possuir um padrão de estrutura de pastas, manual de nomenclatura.

A empresa E é bastante jovem e concentrada em seu titular. Algumas das dificuldades da empresa são:

(a) concentração de atividades na figura do titular;

(b) estabelecimento de objetivos, metas, ações e indicadores;

(c) seleção, motivação e avaliação do desempenho dos colaboradores;

(d) definição do investimento em marketing; precificação do projeto;

(e) definição do cronograma dos projetos; e

(f) falta de tempo para definir os fluxos do processo de projeto.

146 Paula, N. de; Uechi, M.; Melhado, S. 
A empresa $\mathrm{F}$ presta diversos tipos de serviços, possui quatro sócios, muitas vezes com opiniões bastante divergentes. Assim como na empresa D, há dificuldade em conciliar os papéis de gestores e projetistas. A empresa tende a ser inovadora, principalmente por seu alto interesse pelo BIM. Porém, como não realiza um planejamento estratégico, há falta de foco e, consequentemente, perda de oportunidades no mercado. Algumas de suas dificuldades são:

(a) definição da matriz de responsabilidades da empresa;

(b) dificuldade na definição das áreas de atuação e falta de tempo para discuti-las;

(c) monitoramento de dados em tempo real (controle de horas técnicas versus lucratividade); e

(d) processos de projeto diferentes para os diversos serviços prestados.

Apesar de entender a importância da gestão e da tentativa de trabalhá-la, a empresa $\mathrm{G}$ não apresentou evolução significativa. A empresa possui dependência de um único grande cliente, por isso tem empregado esforço na captação de novos clientes. Algumas de suas dificuldades são:

(a) realização do planejamento estratégico;

(b) entendimento do escritório como uma empresa;

(c) definição de perfis, avaliação de desempenho e rotatividade dos colaboradores;

(d) criação de um plano de negócios factível;

(e) captação de novos clientes;

(f) estruturação de um novo processo de projeto e de uma nova equipe de trabalho, responsável por esses clientes, com capacidade de se sustentar financeiramente;

(g) gerenciamento dessa equipe por um dos sócios, desvinculando-o da rotina do resto da empresa; e

(h) dados e informações dispersos no servidor.

\section{Trabalho referente às demandas de mercado com as empresas de projeto}

As demandas de mercado foram inseridas como módulos na sistemática de trabalho do PDGEP 5 (Figura 3), ou seja, se juntaram aos módulos do modelo de gestão. Entre o total de reuniões realizadas no programa (14 reuniões), dez foram destinadas aos módulos, alguns foram tratados em conjunto, e as demandas tiveram uma reunião para cada uma. Desempenho de edifícios foi o terceiro tema trabalhado, sustentabilidade ambiental foi $o$ oitavo, e o BIM foi o décimo e último.

Como já mencionado, três palestras foram realizadas com especialistas do mercado para promover a discussão sobre os temas. Foram realizados diagnósticos para verificar se as demandas estavam sendo consideradas pelas empresas anteriormente ao programa, ou seja, se estavam promovendo alguma ação, seja de preparação para atendê-las, de capacitação ou de trabalho de projeto. As tarefas solicitadas às empresas são apresentadas a seguir.

Sobre desempenho de edifícios: Escolha um requisito de desempenho e, para determinado projeto da empresa, analise se o requisito foi atendido nesse projeto.

Sobre sustentabilidade ambiental de edifícios: Considere uma das categorias do Processo AQUA e, para determinado projeto da empresa, analise se o certificado seria obtido nesse projeto.

Sobre BIM: Elabore um plano para a implementação do BIM na empresa de projeto. Faça a relação do plano com os módulos do Soluções. Qual a relação da implementação do BIM com o módulo de planejamento estratégico, gestão de pessoas, etc.?

O Quadro 3 é um retrato do trabalho realizado em relação às demandas no contexto do PDGEP 5, ou seja, da implementação do modelo de gestão, considerando as diferentes fontes de dados.

Os dados apresentados no Quadro 3 são discutidos na seção Análise de Dados e Discussão. 
Quadro 3 - Trabalho referente às demandas de mercado com as empresas de projeto no contexto do PDGEP 5 (continua)

\begin{tabular}{|c|c|c|c|c|c|c|}
\hline 总 & 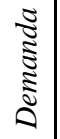 & Diagnóstico & Tarefa & $\begin{array}{l}\text { Relatório do } \\
\text { colaborador }\end{array}$ & $\begin{array}{l}\text { Visita às } \\
\text { empresas }\end{array}$ & $\begin{array}{c}\text { Lições } \\
\text { aprendidas pela } \\
\text { empresa }\end{array}$ \\
\hline \multirow{3}{*}{$A$} & 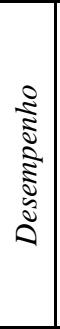 & $\begin{array}{l}\text { Demanda } \\
\text { considerada na } \\
\text { empresa. } \\
\text { Acompanhamento } \\
\text { de ensaios técnicos } \\
\text { feitos pelos } \\
\text { fabricantes de } \\
\text { esquadrias. }\end{array}$ & $\begin{array}{l}\text { Trabalhou } \\
\text { desempenho } \\
\text { térmico e acústico } \\
\text { de uma esquadria. }\end{array}$ & $\begin{array}{l}\text { Apontou a } \\
\text { necessidade de } \\
\text { atualização dos } \\
\text { colaboradores e a } \\
\text { conscientização dos } \\
\text { clientes sobre a } \\
\text { importância do } \\
\text { conceito. }\end{array}$ & $\begin{array}{l}\text { Os requisitos } \\
\text { importantes à } \\
\text { empresa foram } \\
\text { os trabalhados } \\
\text { na tarefa - } \\
\text { relação com } \\
\text { esquadrias. }\end{array}$ & $\begin{array}{l}\text { Falta de } \\
\text { documentação e } \\
\text { ensaio de } \\
\text { produtos } \\
\text { brasileiros. } \\
\text { Falta de } \\
\text { especificação no } \\
\text { projeto de } \\
\text { arquitetura. }\end{array}$ \\
\hline & 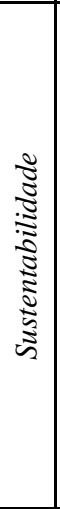 & $\begin{array}{l}\text { Demanda } \\
\text { considerada na } \\
\text { empresa. } \\
\text { Participou de } \\
\text { empreendimentos } \\
\text { com requisitos } \\
\text { ambientais. }\end{array}$ & $\begin{array}{l}\text { Apresentou o caso } \\
\text { de um edifício que } \\
\text { obteve certificação } \\
\text { LEED, dando } \\
\text { ênfase em sua } \\
\text { atuação - } \\
\text { esquadrias e } \\
\text { fachadas. }\end{array}$ & $\begin{array}{l}\text { Apontou que a } \\
\text { empresa não tem } \\
\text { grandes dificuldades. } \\
\text { Entende que o BIM } \\
\text { poderá contribuir com } \\
\text { a sustentabilidade do } \\
\text { edifício. }\end{array}$ & $\begin{array}{l}\text { A empresa } \\
\text { trabalhou com } \\
\text { requisitos } \\
\text { ambientais } \\
\text { anteriormente } \\
\text { ao programa, } \\
\text { mas realizou a } \\
\text { discussão sobre } \\
\text { a demanda. }\end{array}$ & $\begin{array}{l}\text { Falta de } \\
\text { informação } \\
\text { técnica e } \\
\text { produtos } \\
\text { testados. } \\
\text { O quanto o } \\
\text { projeto de } \\
\text { esquadrias } \\
\text { deveria ser } \\
\text { alterado para que } \\
\text { o edifício } \\
\text { alcançasse níveis } \\
\text { de eficiência } \\
\text { satisfatórios. }\end{array}$ \\
\hline & $\underset{\infty}{\Sigma}$ & $\begin{array}{l}\text { Demanda } \\
\text { considerada na } \\
\text { empresa. } \\
\text { Interesse na } \\
\text { implementação } \\
\text { após a mudança } \\
\text { física da empresa. }\end{array}$ & $\begin{array}{l}\text { Realizou um plano } \\
\text { para } \\
\text { implementação, } \\
\text { considerando prazo, } \\
\text { investimento, } \\
\text { consultoria BIM e } \\
\text { software. }\end{array}$ & $\begin{array}{l}\text { Apontou a } \\
\text { implementação do } \\
\text { BIM com o objetivo } \\
\text { de aumentar a } \\
\text { eficiência interna. }\end{array}$ & $\begin{array}{l}\text { Enfoque nos } \\
\text { módulos de } \\
\text { gestão. }\end{array}$ & $\begin{array}{l}\text { Realização do } \\
\text { plano. }\end{array}$ \\
\hline \multirow{3}{*}{$B$} & 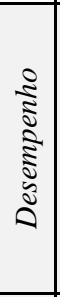 & $\begin{array}{l}\text { Demanda não } \\
\text { considerada na } \\
\text { empresa. } \\
\text { No aguardo das } \\
\text { definições do } \\
\text { mercado sobre sua } \\
\text { atuação em relação } \\
\text { à norma. }\end{array}$ & Não realizada. & $\begin{array}{l}\text { Apontou que não } \\
\text { foram encontradas } \\
\text { formas diretas de } \\
\text { aplicação da norma } \\
\text { nos projetos da } \\
\text { empresa, o que } \\
\text { inviabilizou a } \\
\text { realização da tarefa. }\end{array}$ & $\begin{array}{l}\text { Necessidade de } \\
\text { levantamento de } \\
\text { softwares de } \\
\text { simulação } \\
\text { energética, } \\
\text { envolvendo a } \\
\text { equipe de } \\
\text { projeto. }\end{array}$ & $\begin{array}{l}\text { Necessidade de } \\
\text { estudo da } \\
\text { aplicação de } \\
\text { softwares de } \\
\text { medição de } \\
\text { desempenho. }\end{array}$ \\
\hline & 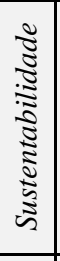 & $\begin{array}{l}\text { Demanda } \\
\text { considerada na } \\
\text { empresa. Participou } \\
\text { de } \\
\text { empreendimentos } \\
\text { com requisitos } \\
\text { ambientais. } \\
\end{array}$ & Não realizada. & $\begin{array}{l}\text { Apontou a ênfase da } \\
\text { empresa no controle } \\
\text { de horas despendidas } \\
\text { no projeto e descrição } \\
\text { de cargos. }\end{array}$ & $\begin{array}{l}\text { Enfoque nos } \\
\text { módulos de } \\
\text { gestão. }\end{array}$ & $\begin{array}{l}\text { Importância da } \\
\text { gestão para a } \\
\text { empresa. }\end{array}$ \\
\hline & $\underset{\infty}{\Sigma}$ & $\begin{array}{l}\text { Demanda } \\
\text { considerada na } \\
\text { empresa. } \\
\text { Perspectiva de o } \\
\text { BIM ser adotado } \\
\text { em um projeto } \\
\text { contratado. }\end{array}$ & Não realizada. & $\begin{array}{l}\text { Apontou a ênfase da } \\
\text { empresa no controle } \\
\text { de horas despendidas } \\
\text { no projeto e descrição } \\
\text { de cargos. }\end{array}$ & $\begin{array}{l}\text { Enfoque nos } \\
\text { módulos de } \\
\text { gestão. }\end{array}$ & $\begin{array}{l}\text { Importância da } \\
\text { gestão para a } \\
\text { empresa. }\end{array}$ \\
\hline
\end{tabular}


Quadro 3 - Trabalho referente às demandas de mercado com as empresas de projeto no contexto do PDGEP 5 (continuação)

\begin{tabular}{|c|c|c|c|c|c|c|}
\hline 离 & 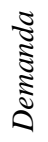 & Diagnóstico & Tarefa & $\begin{array}{l}\text { Relatório do } \\
\text { colaborador }\end{array}$ & $\begin{array}{l}\text { Visita às } \\
\text { empresas }\end{array}$ & $\begin{array}{l}\text { Lições } \\
\text { aprendidas pela } \\
\text { empresa }\end{array}$ \\
\hline \multirow{3}{*}{$C$} & 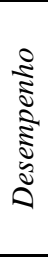 & $\begin{array}{l}\text { Demanda } \\
\text { considerada na } \\
\text { empresa. } \\
\text { Estudo da norma. }\end{array}$ & $\begin{array}{l}\text { Realizou a } \\
\text { discussão da } \\
\text { norma, encontrou } \\
\text { disparidades entre } \\
\text { ela e outras } \\
\text { normas que } \\
\text { utilizam. } \\
\end{array}$ & $\begin{array}{l}\text { Apontou conflitos entre } \\
\text { normas. }\end{array}$ & $\begin{array}{l}\text { Necessidade de } \\
\text { tirar as dúvidas } \\
\text { sobre a norma, } \\
\text { contatando } \\
\text { especialista que } \\
\text { ministrou a } \\
\text { palestra. } \\
\end{array}$ & $\begin{array}{l}\text { Importância da } \\
\text { atualização da } \\
\text { empresa em } \\
\text { relação à norma. }\end{array}$ \\
\hline & 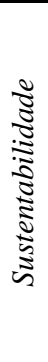 & $\begin{array}{l}\text { Demanda } \\
\text { considerada na } \\
\text { empresa. } \\
\text { Participou de } \\
\text { empreendimentos } \\
\text { com requisitos } \\
\text { ambientais. }\end{array}$ & $\begin{array}{l}\text { Trabalhou a } \\
\text { categoria gestão } \\
\text { da água do } \\
\text { Processo AQUA. }\end{array}$ & $\begin{array}{l}\text { Apontou a experiência } \\
\text { da empresa com o } \\
\text { LEED. }\end{array}$ & $\begin{array}{l}\text { Enfoque nos } \\
\text { módulos de } \\
\text { gestão. }\end{array}$ & $\begin{array}{l}\text { Conhecimento } \\
\text { do Processo } \\
\text { AQUA, } \\
\text { permitindo a } \\
\text { apresentação de } \\
\text { estudos de } \\
\text { viabilidade da } \\
\text { certificação para } \\
\text { um edifício (caso } \\
\text { real). }\end{array}$ \\
\hline & 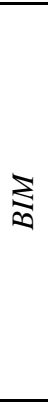 & $\begin{array}{l}\text { Demanda } \\
\text { considerada na } \\
\text { empresa. } \\
\text { Realização de } \\
\text { trabalhos em } \\
\text { BIM. }\end{array}$ & $\begin{array}{l}\text { Elaborou um } \\
\text { mapa mental } \\
\text { sobre a } \\
\text { implementação } \\
\text { ideal, } \\
\text { considerando } \\
\text { custos, software, } \\
\text { hardware, } \\
\text { pessoas, processo } \\
\text { de projeto e } \\
\text { projeto piloto. }\end{array}$ & $\begin{array}{l}\text { Enfoque nos módulos } \\
\text { de gestão. }\end{array}$ & $\begin{array}{l}\text { Enfoque nos } \\
\text { módulos de } \\
\text { gestão. }\end{array}$ & $\begin{array}{l}\text { Entendimento } \\
\text { dos vários } \\
\text { aspectos que } \\
\text { implicam a } \\
\text { implementação } \\
\text { do BIM. }\end{array}$ \\
\hline \multirow{3}{*}{$D$} & 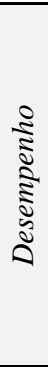 & $\begin{array}{l}\text { Demanda não } \\
\text { considerada na } \\
\text { empresa. } \\
\text { Desconhecimento } \\
\text { da existência da } \\
\text { norma. }\end{array}$ & Não realizada. & $\begin{array}{l}\text { Apontou o pouco } \\
\text { interesse da empresa em } \\
\text { relação ao tema. Isso se } \\
\text { deve ao fato de a norma } \\
\text { só entrar em vigor em } \\
2012 \text { e de haver pouca } \\
\text { ou nenhuma procura } \\
\text { pelos requisitos da } \\
\text { norma por parte dos } \\
\text { clientes atuais. }\end{array}$ & $\begin{array}{l}\text { Necessidade de } \\
\text { elaboração de } \\
\text { um cronograma } \\
\text { para se preparar } \\
\text { em relação à } \\
\text { norma. }\end{array}$ & $\begin{array}{l}\text { Importância da } \\
\text { atualização da } \\
\text { empresa em } \\
\text { relação à norma. } \\
\text { Importância da } \\
\text { gestão para a } \\
\text { empresa. }\end{array}$ \\
\hline & 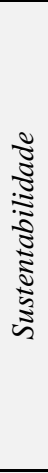 & $\begin{array}{l}\text { Demanda não } \\
\text { considerada na } \\
\text { empresa. } \\
\text { Possui } \\
\text { conhecimento da } \\
\text { existência apenas. }\end{array}$ & $\begin{array}{l}\text { Realizou apenas } \\
\text { leitura do } \\
\text { Processo AQUA e } \\
\text { apresentação de } \\
\text { um resumo. }\end{array}$ & $\begin{array}{l}\text { Apontou que a empresa } \\
\text { possui pouca } \\
\text { experiência com } \\
\text { projetos que buscam } \\
\text { certificação ambiental, e } \\
\text { nas poucas vezes em } \\
\text { que tiveram contato, o } \\
\text { projeto não seguiu em } \\
\text { frente devido ao custo } \\
\text { elevado que a } \\
\text { certificação agregou. } \\
\text { Enfoque nos módulos } \\
\text { de gestão. }\end{array}$ & $\begin{array}{l}\text { Enfoque nos } \\
\text { módulos de } \\
\text { gestão. }\end{array}$ & $\begin{array}{l}\text { Importância da } \\
\text { gestão para a } \\
\text { empresa. }\end{array}$ \\
\hline & 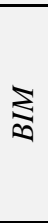 & $\begin{array}{l}\text { Demanda não } \\
\text { considerada na } \\
\text { empresa. } \\
\text { Nenhuma ação } \\
\text { em relação ao } \\
\text { BIM. }\end{array}$ & Não realizada. & $\begin{array}{l}\text { Enfoque nos módulos } \\
\text { de gestão. }\end{array}$ & $\begin{array}{l}\text { Enfoque nos } \\
\text { módulos de } \\
\text { gestão. }\end{array}$ & $\begin{array}{l}\text { Importância da } \\
\text { gestão para a } \\
\text { empresa. }\end{array}$ \\
\hline
\end{tabular}


Quadro 3 - Trabalho referente às demandas de mercado com as empresas de projeto no contexto do PDGEP 5 (continuação)

\begin{tabular}{|c|c|c|c|c|c|c|}
\hline 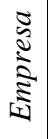 & 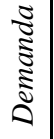 & Diagnóstico & Tarefa & $\begin{array}{l}\text { Relatório do } \\
\text { colaborador }\end{array}$ & Visita às empresas & $\begin{array}{l}\text { Lições aprendidas } \\
\text { pela empresa }\end{array}$ \\
\hline \multirow{3}{*}{$E$} & 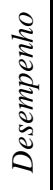 & $\begin{array}{l}\text { Demanda não } \\
\text { considerada na } \\
\text { empresa. } \\
\text { Nenhuma ação em } \\
\text { relação à norma. }\end{array}$ & Não realizada. & $\begin{array}{l}\text { Enfoque nos } \\
\text { módulos de } \\
\text { gestão. }\end{array}$ & $\begin{array}{l}\text { Necessidade de } \\
\text { elaboração de um } \\
\text { cronograma para } \\
\text { se preparar em } \\
\text { relação à norma. }\end{array}$ & $\begin{array}{l}\text { Necessidade de } \\
\text { treinamentos } \\
\text { relacionados à } \\
\text { norma. }\end{array}$ \\
\hline & 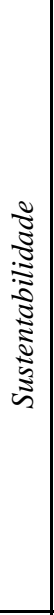 & $\begin{array}{l}\text { Demanda não } \\
\text { considerada na } \\
\text { empresa. } \\
\text { Nenhuma ação em } \\
\text { relação à } \\
\text { sustentabilidade. }\end{array}$ & $\begin{array}{l}\text { Trabalhou as categorias } \\
\text { escolha de produtos, } \\
\text { gestão da água e } \\
\text { conforto visual do } \\
\text { Processo AQUA. }\end{array}$ & $\begin{array}{l}\text { Enfoque nos } \\
\text { módulos de } \\
\text { gestão. }\end{array}$ & $\begin{array}{l}\text { Enfoque nos } \\
\text { módulos de } \\
\text { gestão. }\end{array}$ & $\begin{array}{l}\text { Necessidades: } \\
\text { busca de } \\
\text { fornecedores } \\
\text { certificados e com } \\
\text { produtos } \\
\text { especificados; } \\
\text { conhecimento } \\
\text { técnico de } \\
\text { requisitos } \\
\text { específicos como } \\
\text { iluminância, normas } \\
\text { de acessibilidade; } \\
\text { conhecimento dos } \\
\text { processos } \\
\text { produtivos dos } \\
\text { materiais para } \\
\text { orientar escolhas. }\end{array}$ \\
\hline & $\underset{\emptyset}{\lessgtr}$ & $\begin{array}{l}\text { Demanda não } \\
\text { considerada na } \\
\text { empresa. } \\
\text { Nenhuma ação em } \\
\text { relação ao BIM. }\end{array}$ & $\begin{array}{l}\text { Definiu estratégias para } \\
\text { a implementação do } \\
\text { BIM, considerando } \\
\text { análise de softwares, } \\
\text { uso do BIM de acordo } \\
\text { com a atuação da } \\
\text { empresa, planejamento } \\
\text { financeiro e } \\
\text { treinamentos. }\end{array}$ & $\begin{array}{l}\text { Enfoque nos } \\
\text { módulos de } \\
\text { gestão. }\end{array}$ & $\begin{array}{l}\text { Enfoque nos } \\
\text { módulos de } \\
\text { gestão. }\end{array}$ & $\begin{array}{l}\text { Definição de } \\
\text { estratégias. } \\
\text { Obrigou a pensar no } \\
\text { futuro, de modo a } \\
\text { definir objetivos e } \\
\text { metas. } \\
\text { Importância da } \\
\text { gestão para a } \\
\text { empresa. } \\
\end{array}$ \\
\hline \multirow{3}{*}{$F$} & 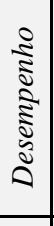 & $\begin{array}{l}\text { Demanda não } \\
\text { considerada na } \\
\text { empresa. } \\
\text { Nenhuma ação } \\
\text { relacionada à } \\
\text { norma. }\end{array}$ & $\begin{array}{l}\text { Trabalhou o requisito } \\
\text { saúde, higiene e } \\
\text { qualidade do ar da } \\
\text { norma. }\end{array}$ & $\begin{array}{l}\text { Enfoque nos } \\
\text { módulos de } \\
\text { gestão. }\end{array}$ & $\begin{array}{l}\text { Necessidade de } \\
\text { elaboração de um } \\
\text { cronograma para } \\
\text { se preparar em } \\
\text { relação à norma. }\end{array}$ & $\begin{array}{l}\text { Necessidade de } \\
\text { preparar-se para } \\
\text { atender ao mercado. }\end{array}$ \\
\hline & 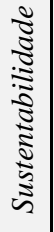 & $\begin{array}{l}\text { Demanda não } \\
\text { considerada na } \\
\text { empresa. } \\
\text { Nenhuma ação } \\
\text { relacionada à } \\
\text { sustentabilidade. }\end{array}$ & Não realizada. & $\begin{array}{l}\text { Enfoque nos } \\
\text { módulos de } \\
\text { gestão. }\end{array}$ & $\begin{array}{l}\text { Enfoque nos } \\
\text { módulos de } \\
\text { gestão. }\end{array}$ & $\begin{array}{l}\text { A empresa está } \\
\text { afastada do tema, } \\
\text { necessidade de } \\
\text { reflexão. }\end{array}$ \\
\hline & $\underset{\infty}{ミ}$ & $\begin{array}{l}\text { Demanda não } \\
\text { considerada na } \\
\text { empresa. } \\
\text { Utiliza um software } \\
\text { BIM, trata-se de } \\
\text { uma motivação } \\
\text { interna, não percebe } \\
\text { a demanda e não } \\
\text { considera o BIM } \\
\text { como processo, } \\
\text { conceito. } \\
\end{array}$ & $\begin{array}{l}\text { Apresentou como } \\
\text { iniciou a utilização do } \\
\text { software BIM. }\end{array}$ & $\begin{array}{l}\text { Enfoque nos } \\
\text { módulos de } \\
\text { gestão. }\end{array}$ & $\begin{array}{l}\text { Enfoque nos } \\
\text { módulos de } \\
\text { gestão. }\end{array}$ & $\begin{array}{l}\text { Há dificuldade no } \\
\text { aproveitamento das } \\
\text { oportunidades do } \\
\text { mercado por parte } \\
\text { da empresa, ou seja, } \\
\text { em aproveitar a } \\
\text { demanda existente. } \\
\text { Obteve informação } \\
\text { sobre o mercado no } \\
\text { PDGEP. }\end{array}$ \\
\hline
\end{tabular}


Quadro 3 - Trabalho referente às demandas de mercado com as empresas de projeto no contexto do PDGEP 5 (continuação)

\begin{tabular}{|c|c|c|c|c|c|c|}
\hline 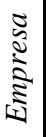 & 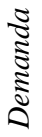 & Diagnóstico & Tarefa & $\begin{array}{l}\text { Relatório do } \\
\text { colaborador }\end{array}$ & Visita às empresas & $\begin{array}{l}\text { Liçôes aprendidas } \\
\text { pela empresa }\end{array}$ \\
\hline \multirow{3}{*}{$G$} & 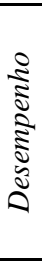 & $\begin{array}{l}\text { Demanda não } \\
\text { considerada na } \\
\text { empresa. } \\
\text { Nenhuma ação } \\
\text { em relação à } \\
\text { norma. }\end{array}$ & $\begin{array}{l}\text { Apresentou um plano } \\
\text { de ação para se } \\
\text { preparar em relação à } \\
\text { norma. }\end{array}$ & $\begin{array}{l}\text { Realizar } \\
\text { projetos que } \\
\text { contemplem a } \\
\text { nova norma é } \\
\text { algo nebuloso } \\
\text { para a } \\
\text { empresa. } \\
\end{array}$ & $\begin{array}{l}\text { Necessidade de } \\
\text { elaboração de um } \\
\text { cronograma para se } \\
\text { preparar em relação } \\
\text { à norma. }\end{array}$ & $\begin{array}{l}\text { Importância da } \\
\text { atualização da } \\
\text { empresa em relação } \\
\text { à norma. }\end{array}$ \\
\hline & 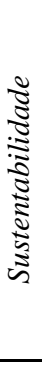 & $\begin{array}{l}\text { Demanda não } \\
\text { considerada na } \\
\text { empresa. } \\
\text { Nenhuma ação } \\
\text { em relação à } \\
\text { sustentabilidade. }\end{array}$ & $\begin{array}{l}\text { Apresentou uma } \\
\text { ferramenta para } \\
\text { auxiliar no } \\
\text { desenvolvimento de } \\
\text { projetos sustentáveis. }\end{array}$ & $\begin{array}{l}\text { Realizou } \\
\text { considerações } \\
\text { sobre a } \\
\text { ferramenta } \\
\text { criada. Trata- } \\
\text { se de um } \\
\text { check-list de } \\
\text { possíveis } \\
\text { soluções } \\
\text { sustentáveis. } \\
\end{array}$ & $\begin{array}{l}\text { Enfoque nos } \\
\text { módulos de gestão. }\end{array}$ & $\begin{array}{l}\text { Necessidade de } \\
\text { conhecimento sobre } \\
\text { o tema. }\end{array}$ \\
\hline & 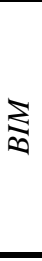 & $\begin{array}{l}\text { Demanda não } \\
\text { considerada na } \\
\text { empresa. } \\
\text { Nenhuma ação } \\
\text { em relação ao } \\
\text { BIM. }\end{array}$ & $\begin{array}{l}\text { Apresentou algumas } \\
\text { ações em relação ao } \\
\text { BIM, como entrar em } \\
\text { contato com os } \\
\text { softwares. }\end{array}$ & $\begin{array}{l}\text { Enfoque nos } \\
\text { módulos de } \\
\text { gestão. }\end{array}$ & $\begin{array}{l}\text { Enfoque nos } \\
\text { módulos de gestão. }\end{array}$ & $\begin{array}{l}\text { Necessidade de } \\
\text { entrar em contato } \\
\text { com os softwares } \\
\text { BIM. } \\
\text { Importância da } \\
\text { gestão para a } \\
\text { empresa. }\end{array}$ \\
\hline
\end{tabular}

\section{Posicionamento das empresas de projeto em relação às demandas de mercado}

Os resultados da Fase 2 de pesquisa são apresentados nos Quadros 4, 5, 6 e 7. O Quadro 4 apresenta os resultados referentes à consideração da demanda de desempenho de edifícios pelas empresas de projeto.

A empresa A tem acompanhado as normas de esquadrias que estão sendo revisadas em conformidade com a norma de desempenho; uma de suas grandes preocupações é quanto aos dados oficiais dos produtos (janela, porta, etc.) que não existem nos catálogos; acredita que haverá uma melhoria nos projetos, já que a norma passará a exigir os requisitos de desempenho dos edifícios. A empresa B não sabe exatamente como a norma irá influenciar seu trabalho, pois considera que ela não trata diretamente de sua especialidade. A empresa $\mathrm{C}$ entende que a norma será aplicada pela exigência legal, nem tanto pelo mercado, e está realizando discussão internas sobre ela. A empresa G também está realizando discussões internas; segundo a empresa, os arquitetos sempre buscaram produtos de boa qualidade, que atendam às exigências dos usuários, assim a norma veio para estruturar e parametrizar uma conduta que já é aplicada nos projetos de edifícios. As empresas D, $\mathrm{E}$ e $\mathrm{F}$ não têm feito preparação para atender à norma - segundo a empresa E, sua dificuldade se refere à falta de tempo.

Segundo o arquiteto titular da empresa D,

[...] acredito que não haja dificuldades [na aplicação da norma de desempenho], e sim algumas adaptações em alguns pontos que hoje pensamos de uma maneira e que será de outra $[. .$.$] .$

Segundo um dos sócios da empresa F,

[...] o primeiro passo será exigir de todos os parceiros informações sobre o atual estado de implementação da norma dentro da própria estrutura, e, em paralelo, estabelecer um plano para consolidação no processo dentro do escritório[...].

O Quadro 5 apresenta os resultados sobre a consideração da demanda de sustentabilidade ambiental de edifícios pelas empresas de projeto.

A empresa A considera as exigências de desempenho e sustentabilidade em seus projetos há pelo menos 4 anos; participou recentemente de um seminário sobre a certificação pela entidade alemã DGNB (em inglês, German Sustainable Building Council). A empresa B participa de projetos que 
almejam a certificação LEED; acredita que o atual interesse dos empreendedores por sustentabilidade é mais no aspecto mercadológico do que filosófico; como a manutenção das instalações é usualmente precária, é difícil saber se a edificação e suas instalações manterão suas características originais durante sua vida útil.

A empresa $C$ participa de empreendimentos que visam à certificação ambiental; segundo um de seus diretores,

\section{[...] no início, há alguns anos, havia a dificuldade de viabilizar os requisitos de sustentabilidade por um problema de timing. Por vezes os consultores eram contratados no final do projeto, inviabilizando a implementação de vários requisitos. Atualmente, o consultor de sustentabilidade já participa desde o início do projeto, delineando antecipadamente os requisitos e facilitando todo o processo [...].}

Em 2012, a empresa D venceu um concurso nacional para os estudos preliminares da sede de dois órgãos; os projetos apresentados deveriam conter sete princípios: mobilidade, eficiência energética, gestão de água, paisagem, materiais e resíduos, evolução e inovação, e responsabilidade social; ela teve algumas dificuldades devido à falta de conhecimento aprofundado em itens específicos. Para a empresa E, o interesse por sustentabilidade ambiental é crescente, entende que precisa se preparar para essa demanda.

Apesar de não ter participado de empreendimentos com exigências ambientais, para a empresa $\mathrm{F}$, haverá cada vez mais modificações no produto final, que passará a incorporar os requisitos ambientais; apesar desse discurso, a empresa citou dificuldades, como a falta de tempo para se capacitar e a necessidade de investimentos para trabalhar a demanda. Para a empresa G, "todos estão se familiarizando com esses termos e estão tomando consciência da sua real importância".

O Quadro 6 apresenta os resultados referentes à consideração do BIM pelas empresas de projeto.

\section{Quadro 4 - Demanda de desempenho de edifícios}

\begin{tabular}{|c|c|c|c|}
\hline 莺 & $\begin{array}{c}\text { Possui exemplar da norma } \\
\text { de desempenho }(\mathrm{NBR} \\
\text { 15575)? }\end{array}$ & $\begin{array}{c}\text { Tem conhecimento sobre a } \\
\text { norma? }\end{array}$ & $\begin{array}{c}\text { Tem feito alguma preparação } \\
\text { para atender à norma? }\end{array}$ \\
\hline $\mathrm{A}$ & Sim & Sim & Sim \\
\hline $\mathrm{B}$ & Sim, Parte 1 & Superficial & Não \\
\hline $\mathrm{C}$ & Sim & Sim & Sim \\
\hline $\mathrm{D}$ & Sim & Não & Não \\
\hline$E$ & Sim & Superficial & Não \\
\hline $\mathrm{F}$ & Sim & Superficial & Não \\
\hline $\mathrm{G}$ & Sim & Sim & Sim \\
\hline
\end{tabular}

\section{Quadro 5 - Demanda de sustentabilidade ambiental de edifícios}

\begin{tabular}{|c|c|c|c|}
\hline 苞 & $\begin{array}{l}\text { Participou de } \\
\text { empreendimentos } \\
\text { com exigências } \\
\text { ambientais? }\end{array}$ & $\begin{array}{l}\text { Conhece algum } \\
\text { processo de } \\
\text { certificação } \\
\text { ambiental? }\end{array}$ & $\begin{array}{c}\text { Quais competências acredita ser necessárias } \\
\text { para trabalhar os requisitos ambientais? }\end{array}$ \\
\hline A & Sim & $\begin{array}{l}\text { LEED, AQUA e } \\
\text { DGNB }\end{array}$ & $\begin{array}{l}\text { Ser arquiteto, engenheiro, ciências ambientais, } \\
\text { tecnólogo e afins, experiência profissional. }\end{array}$ \\
\hline $\mathrm{B}$ & Sim & LEED & $\begin{array}{l}\text { Conhecimento e atendimento às normas e } \\
\text { regulamentos pertinentes. }\end{array}$ \\
\hline $\mathrm{C}$ & Sim & LEED e AQUA & Resposta não obtida. \\
\hline $\mathrm{D}$ & Sim & LEED & Amplo conhecimento sobre o assunto. \\
\hline $\mathrm{E}$ & Não & AQUA & Informação. \\
\hline $\mathrm{F}$ & Não & LEED & $\begin{array}{l}\text { Conhecimento de tecnologia adequada, sobre o } \\
\text { comportamento de materiais e do clima, e sobre } \\
\text { certificação. }\end{array}$ \\
\hline $\mathrm{G}$ & Não & LEED e AQUA & Não requerem competências especiais. \\
\hline
\end{tabular}

152 Paula, N. de; Uechi, M.; Melhado, S. 
Quadro 6 - Demanda de BIM

\begin{tabular}{|c|c|c|c|}
\hline 总 & $\begin{array}{l}\text { Possui práticas } \\
\text { relacionadas ao BIM? } \\
\text { Há quanto tempo } \\
\text { iniciou as práticas? }\end{array}$ & $\begin{array}{c}\text { O que levou a empresa a iniciar } \\
\text { as práticas? } \\
\text { Qual software foi escolhido e por } \\
\text { quê? }\end{array}$ & $\begin{array}{l}\text { Quais estratégias foram adotadas } \\
\text { para a implementação do BIM? }\end{array}$ \\
\hline $\mathrm{A}$ & $\begin{array}{l}\text { Sim } \\
1 \text { ano }\end{array}$ & $\begin{array}{l}\text { Plataforma do futuro; facilitar } \\
\text { visualização do projeto; participar } \\
\text { em projetos com maior valor } \\
\text { agregado; extrair informações; } \\
\text { fazer a interface do projeto da } \\
\text { empresa com o de fabricação. } \\
\text { Revit; melhor resposta para o } \\
\text { negócio e a maioria dos arquitetos } \\
\text { utiliza. }\end{array}$ & $\begin{array}{l}\text { Primeiro verificou-se a qualidade } \\
\text { da rede, servidor e máquinas. } \\
\text { Contrataram um arquiteto que } \\
\text { ministrou o curso de Revit na } \\
\text { empresa; posteriormente, } \\
\text { contrataram uma consultoria para } \\
\text { documentar e auxiliar na } \\
\text { montagem das famílias. }\end{array}$ \\
\hline B & $\begin{array}{c}\text { Sim } \\
2 \text { anos }\end{array}$ & $\begin{array}{l}\text { Parceria com cliente. } \\
\text { DDS; inicialmente por acordo } \\
\text { com o cliente e posteriormente } \\
\text { por custo mais vantajoso e } \\
\text { disponibilidade de treinamento. }\end{array}$ & $\begin{array}{l}\text { Há uma equipe trabalhando com o } \\
\text { DDS nos projetos do cliente } \\
\text { parceiro (irá disseminar o } \\
\text { aprendizado às demais); outra } \\
\text { equipe está avaliando o Revit } \\
\text { devido à predominância no } \\
\text { mercado. }\end{array}$ \\
\hline $\mathrm{C}$ & $\begin{array}{l}\text { Sim } \\
4 \text { anos }\end{array}$ & $\begin{array}{l}\text { Percepção de mercado e } \\
\text { posicionamento estratégico. } \\
\text { Revit MEP; opção adotada pela } \\
\text { maioria dos arquitetos parceiros e } \\
\text { pela confiança na empresa de } \\
\text { software. }\end{array}$ & $\begin{array}{l}\text { Iniciaram com um projeto piloto } \\
\text { simples, quase todos os } \\
\text { colaboradores foram treinados e } \\
\text { contrataram um profissional } \\
\text { dedicado à implementação, } \\
\text { desenvolvimento e suporte aos } \\
\text { demais colaboradores. }\end{array}$ \\
\hline $\mathrm{D}$ & Não & Não se aplica & Não se aplica \\
\hline $\mathrm{E}$ & Não & Não se aplica & Não se aplica \\
\hline $\mathrm{F}$ & $\begin{array}{l}\text { Sim } \\
7 \text { Anos }\end{array}$ & $\begin{array}{l}\text { Acredita no processo de projeto } \\
\text { BIM. } \\
\text { Revit; mais adequado para suas } \\
\text { preocupações de projeto. }\end{array}$ & $\begin{array}{l}\text { Desenvolvimento de biblioteca e } \\
\text { construção de template; } \\
\text { treinamento dos colaboradores. }\end{array}$ \\
\hline $\mathrm{G}$ & Não & Não se aplica & Não se aplica \\
\hline
\end{tabular}

As empresas A e B recebem solicitações de trabalho em BIM, assim como a empresa $\mathrm{C}$, que citou algumas dificuldades em relação ao conceito: adaptação aos novos processos de projetos, treinamento de colaboradores, preço de software e hardware, baixa produtividade inicial, etc. Para a empresa F, que adotou o BIM por motivação própria, o custo do software é o maior obstáculo hoje. Outras dificuldades se referem:

(a) ao aproveitamento das oportunidades ligadas ao BIM;

(b) à concentração do conhecimento em poucos membros da equipe;

(c) ao tempo de capacitação da equipe;

(d) à retenção da equipe;

(e) à não utilização do BIM por parte dos demais projetistas; (f) à decisão sobre a utilização de BIM ou CAD, dependendo das condições do projeto.

Um cliente da empresa D expôs que irá exigir todos os trabalhos em BIM em breve. De um modo geral, os clientes das empresas A, B, C e D apresentam exigências em relação ao BIM e à sustentabilidade ambiental; já os clientes das empresas E, F e G não apresentam. A empresa G demonstra ciência de que não pode ficar à margem desses assuntos (demandas), apesar de não ser demandada.

Dados referentes à estrutura de gestão das empresas de projeto, com foco em concorrentes, tomada de decisão e planejamento estratégico também foram coletados na Fase 2 de pesquisa, os quais são apresentados no Quadro 7. Entende-se que a estrutura de gestão tem influência em como as empresas se posicionam diante das demandas de mercado. 
Quadro 7 - Estrutura de gestão das empresas de projeto

\begin{tabular}{|c|c|c|c|}
\hline 宽 & $\begin{array}{c}\text { Conhece o desempenho de seus } \\
\text { concorrentes no mercado? }\end{array}$ & $\begin{array}{l}\text { Como são tomadas as decisões } \\
\text { sobre o futuro da empresa? }\end{array}$ & $\begin{array}{c}\text { Formaliza seu planejamento } \\
\text { estratégico? }\end{array}$ \\
\hline A & $\begin{array}{l}\text { Parcialmente; utiliza } \\
\text { informações de contratantes e de } \\
\text { escritórios de arquitetura } \\
\text { parceiros. }\end{array}$ & $\begin{array}{l}\text { Tem um sistema de gestão do } \\
\text { qual extrai relatórios do } \\
\text { desempenho de cada projeto; } \\
\text { participa de associações e eventos } \\
\text { que fornecem um panorama do } \\
\text { mercado de projetos. }\end{array}$ & $\begin{array}{l}\text { Realizado anualmente; no final de } \\
\text { cada ano é realizada uma reunião } \\
\text { com apresentação do desempenho } \\
\text { da empresa e dos objetivos e } \\
\text { metas para o próximo período. }\end{array}$ \\
\hline B & $\begin{array}{l}\text { Precariamente; por contatos } \\
\text { com instaladores, clientes e } \\
\text { concorrentes. }\end{array}$ & Em reuniões de diretoria. & Não \\
\hline $\mathrm{C}$ & $\begin{array}{l}\text { Participa de entidade que reúne } \\
\text { as empresas concorrentes. }\end{array}$ & Em reuniões entre diretores. & Não \\
\hline $\mathrm{D}$ & $\begin{array}{l}\text { Parcialmente; por conversas } \\
\text { com os colaboradores ou sócios. }\end{array}$ & $\begin{array}{l}\text { Em reuniões entre sócios e } \\
\text { colaboradores. }\end{array}$ & $\begin{array}{l}\text { São planejamentos trimestrais, } \\
\text { semestrais e anuais. }\end{array}$ \\
\hline $\mathrm{E}$ & $\begin{array}{l}\text { Parcialmente; por contato } \\
\text { pessoal, sites e notícias. }\end{array}$ & $\begin{array}{l}\text { Conforme as oportunidades } \\
\text { aparecem. }\end{array}$ & Não \\
\hline $\mathrm{F}$ & $\begin{array}{l}\text { Parcialmente; quando são } \\
\text { amigos ou conhecidos costuma } \\
\text { trocar experiências. }\end{array}$ & Em reuniões entre sócios. & $\begin{array}{l}\text { Realizado anualmente, com } \\
\text { reavaliação semestral. }\end{array}$ \\
\hline G & $\begin{array}{l}\text { Parcialmente; realiza contato em } \\
\text { eventos, como seminários, etc. }\end{array}$ & $\begin{array}{l}\text { O financeiro é restrito aos sócios; } \\
\text { quanto aos objetivos, serviços } \\
\text { oferecidos, mercado e } \\
\text { investimento de recursos, discute } \\
\text { com a equipe. }\end{array}$ & $\begin{array}{l}\text { Em 2012, chegou a formalizar o } \\
\text { planejamento estratégico, mas } \\
\text { não retomou, nem avaliou os } \\
\text { resultados; há resistência da } \\
\text { equipe e dos sócios em trabalhar } \\
\text { com indicadores, avaliações, etc. }\end{array}$ \\
\hline
\end{tabular}

Como mencionado anteriormente, verificou-se que nenhuma das empresas possuía um planejamento estratégico formalizado e colocado em prática; então, elas foram estimuladas a criá-lo. As empresas tiveram muita dificuldade em compreender esse módulo de gestão. Observou-se por meio das tarefas e das visitas que, apesar de o discurso das empresas ser o de que realizam planejamento estratégico, elas não o fazem apropriadamente, ou seja, não definem objetivos, não os desdobram em metas, ações e indicadores. Apenas a empresa D chegou a estruturar um quadro com esses componentes.

\section{Análise de dados e discussão}

As deficiências nas práticas gerenciais encontradas nas empresas de projeto corroboram as deficiências mencionadas por Souza (2009), tais como inexistência de planejamento estratégico; um fluxo de trabalho organizado e ferramentas para controle, análise crítica e retroalimentação do processo de projeto; planos de ação e controles voltados para a gestão de pessoas, etc.

As empresas de projeto tiveram dificuldades ao implementar o modelo de gestão, tais como: conciliação dos papéis do titular como gestor e projetista, sobretudo porque os arquitetos estão muito ligados ao processo criativo do edifício, deixando de lado a gestão - Melhado (2012) destaca essa dificuldade; inclusão da gestão na rotina da empresa; entendimento ou aplicação dos conceitos implícitos no modelo; planejamento e acompanhamento adequado das ações, etc. As empresas apresentaram um comportamento passivo em relação às questões de gestão, postergando as ações necessárias; o programa exige dedicação, e há muitos conceitos envolvidos; pela morosidade, as empresas acumulavam as atividades; os colaboradores de gestão apoiaram os participantes, mas não tinham todas as respostas, então todos tinham de colaborar na solução dos problemas gerenciais.

$\mathrm{O}$ trabalho referente às demandas de mercado foi parcialmente comprometido pelas dificuldades citadas, já que, muitas vezes, as empresas estavam resolvendo questões estruturais de gestão e entendendo sua importância. Por essa razão, algumas tarefas do programa não foram realizadas ou foram alteradas, e muitas visitas dos pesquisadores tiveram enfoque nos módulos de gestão, como pode ser notado no Quadro 3. Apesar disso, as empresas apresentaram algumas lições aprendidas. 
Deve-se ressaltar que o momento do mercado no qual o PDGEP 5 ocorreu foi diferente em comparação com as outras edições; estava bastante aquecido, as empresas estavam com um volume muito grande de trabalho. Ao longo de sua trajetória, o programa possui casos de sucesso que estão descritos nos artigos publicados. A relação de parte deles pode ser encontrada em Souza et al. (2011).

Quanto ao diagnóstico apresentado no Quadro 3 (Fase 1 da pesquisa), as empresas A, B e C apresentaram algumas ações relacionadas à consideração das demandas. É importante destacar que elas foram demandadas por seus clientes, ao contrário das empresas D, E, F e G. Na Fase 2 da pesquisa, observa-se que a empresa $\mathrm{D}$ foi induzida a considerar sustentabilidade ambiental e BIM por exigência de um concurso e de um cliente respectivamente.

O Quadro 8 apresenta o resultado da análise da influência dos fatores que implicam o posicionamento adotado pelas empresas de projeto ante as novas demandas de desempenho, sustentabilidade ambiental de edifícios e BIM, em sua interação com o mercado e clientes. As empresas que possuem semelhanças foram agrupadas por cor.

Conforme o Quadro 8, as empresas A, B e C prestam serviço para clientes que demandam desempenho, sustentabilidade e/ou BIM; porém, $\mathrm{A}^{2}$ e $\mathrm{C}$ podem ser consideradas, com certa variação, empresas inovadoras e dinâmicas, e B pode ser considerada conservadora e lenta ${ }^{3}$. A empresa D foi induzida a considerar sustentabilidade ambiental e BIM recentemente, e a $\mathrm{F}$ não é demandada por seus clientes, porém possui potencial para atender aqueles que expõem exigências relacionadas às demandas (uma lição aprendida por $\mathrm{F}$ foi a de que possui dificuldade em aproveitar as oportunidades do mercado); possuem um comportamento intermediário, com alguma tendência para inovar e o dinamismo. Já E e G atendem clientes que não demandam e possuem um comportamento intermediário.

\footnotetext{
${ }^{2}$ Segundo tarefa do PDGEP, visita e relatório do colaborador, a empresa A estava passando por uma reformulação, prevendo novo espaço físico; nova comunicação visual com atualização de toda papelaria, sites, formulários, etc.; criação de fôlder com portfólio simplificado para a divulgação da empresa em congressos, cursos e palestras; prestação de novo serviço fiscalização da produção da matéria-prima e da instalação das esquadrias na obra.

${ }^{3} \mathrm{O}$ relatório do colaborador de $\mathrm{B}$ apontou que, por se tratar de uma empresa com muitos anos, com uma posição firmada no mercado, composta de muitos colaboradores antigos e formada em princípios de gestão também antigos, tende a ter uma posição mais conservadora. Tanto os titulares como parte dos colaboradores não estão habituados com tecnologias recentes, trabalhando por vezes "à mão".
}

Sobre a percepção e o entendimento das demandas, as empresas $\mathrm{A}$ e $\mathrm{C}$ as percebem, as entendem e procuram trabalhá-las; são demandadas pelos clientes, isso faz com que não exista dúvida se devem considerar as demandas ou não; como são inovadoras e dinâmicas, elas se preparam de algum modo para atender às demandas por conta própria e, por isso, com certa variação, se posicionam diante delas. A empresa B é fortemente "puxada" pelo cliente, por isso sente as demandas, mas não há um entendimento com profundidade; B não se posiciona diante das demandas, apenas é "levada" pelo cliente; D e F não se importam com as demandas; como possuem um comportamento intermediário, há dificuldade em entender as demandas do cliente "de ponta" e estabelecer estratégias, ou seja, decidir efetivamente se querem trabalhar as demandas ou não, por isso as empresas não se posicionam diante delas; $E$ e $G$ possuem alguma ciência sobre as demandas, mas não as trabalham, nem se posicionam diante delas; as empresas $E$ e $G$ poderiam trabalhar melhor seus clientes, propondo a inserção das demandas, de modo a agregar valor para o serviço prestado.

As empresas A, B e C são especialistas, o que significa que os trabalhos dessas empresas são focados. Isso facilita, por exemplo, considerar requisitos de desempenho e de sustentabilidade ambiental em suas especialidades ${ }^{4}$; como são inovadoras e dinâmicas (com certa variação), A e $\mathrm{C}$ veem como as empresas parceiras (clientes internos, empresa de arquitetura, por exemplo) se comportam e, assim, se preparam para atender às demandas destes e dos clientes "de ponta"; como é "puxada pelo cliente" e especialista, B acaba por considerar as demandas, mesmo sem haver entendimento sobre elas. Já D e F são empresas de arquitetura, trabalham com criação, o que dificulta, por exemplo, considerar os requisitos, transformar conceitos em ações; por terem um comportamento intermediário e grande parte de clientes "comuns", não há consideração das demandas, nem estratégia, apesar do potencial em trabalhar "clientes de ponta". As empresas E e G também trabalham com criação, mas devido a sua ciência com relação às demandas, poderiam trabalhar seus clientes atuais.

\footnotetext{
${ }^{4}$ Isso foi verificado na realização das tarefas do PDGEP.
} 
Quadro 8 - Análise da influência dos fatores que implicam o posicionamento adotado pelas empresas de projeto ante as novas demandas, em sua interação com o mercado e clientes

\begin{tabular}{|c|c|c|}
\hline Empresa Mercado & $\begin{array}{l}\text { Clientes que } \\
\text { demandam }\end{array}$ & $\begin{array}{l}\text { Clientes que não } \\
\text { demandam }\end{array}$ \\
\hline \multicolumn{3}{|l|}{ Inovadora e dinâmica } \\
\hline Conservadora e lenta & & $\mathbf{E}, \mathbf{G}$ \\
\hline \multicolumn{3}{|l|}{$\begin{array}{l}\text { Percebem e/ou entendem as } \\
\text { demandas }\end{array}$} \\
\hline $\begin{array}{l}\text { Não percebem as demandas e/ou } \\
\text { não entendem }\end{array}$ & & G \\
\hline \multicolumn{3}{|l|}{ Posiciona-se ante as demandas } \\
\hline \multicolumn{3}{|l|}{ Não se posiciona ante as demandas } \\
\hline \multicolumn{3}{|l|}{ Especialista } \\
\hline \multicolumn{3}{|l|}{ Arquitetura } \\
\hline \multicolumn{3}{|l|}{ Boa estrutura de gestão } \\
\hline \multicolumn{3}{|l|}{ Estrutura de gestão precisa evoluir } \\
\hline \multicolumn{3}{|l|}{$\begin{array}{l}\text { Estrutura de gestão compreende as } \\
\text { demandas }\end{array}$} \\
\hline $\begin{array}{l}\text { Estrutura de gestão não } \\
\text { compreende as demandas }\end{array}$ & & -1 \\
\hline
\end{tabular}

Sobre a estrutura de gestão, a empresa A possui um SIG, porém não há uma conexão entre o SIG sistema e as demandas; poderia utilizar melhor, consciente e estrategicamente, sua estrutura de gestão, por meio de poucas ações gerenciais. Já a empresa $\mathrm{C}$ possui uma estrutura frágil, que não compreende as demandas; necessita evoluir por meio de muitas ações. Como B é uma empresa conservadora e lenta, qualquer mudança em gestão é bastante difícil, pois há o pensamento "se até aqui deu certo, vamos continuar fazendo assim"; as demandas não são consideradas em sua gestão; como B atua no mercado há muitos anos e se destaca tecnicamente, os clientes a "puxam" para atender a suas necessidades no que se refere às demandas $^{5}$. D e F possuem uma estrutura de gestão relativamente jovem, procuram implementar mudanças, mas, por não agir estrategicamente, acabam perdendo oportunidades; possuem potencial para atender outros tipos de cliente; as

${ }^{5}$ Isso foi o que aconteceu em relação ao BIM: a empresa B somente iniciou suas práticas devido à parceria com um cliente. 
demandas não são consideradas em sua gestão. Em relação às demais empresas estudadas, E possui a estrutura mais jovem, precisa evoluir muito; não considera as demandas em sua gestão. A empresa $\mathrm{G}$ necessita evoluir por meio de algumas ações gerenciais estratégicas; as demandas são não consideradas em sua gestão.

Muitas vezes os projetistas fazem um discurso que não condiz com a realidade. Como exemplos, podemos citar: o discurso da empresa $\mathrm{G}$ é o de que os arquitetos sempre consideraram desempenho, quando, na realidade, a empresa tem grande dificuldade em transformar conceitos como esse em ações efetivas; o discurso da empresa D é o de que, no que se refere à norma de desempenho, algumas adaptações são necessários, quando, na realidade, a empresa não tem conhecimento sobre os requisitos e critérios da norma. Desse modo, percebe-se que os discursos são carregados de desculpas para evitar o trabalho em gestão, a fim de preparar as empresas para atender às demandas.

\section{Considerações finais}

As demandas de desempenho, sustentabilidade ambiental de edifícios e BIM estão em evidência no mercado. Há diferentes tipos de cliente e empresas de projeto nesse mercado, e a relação entre esses agentes ocorre de modo também diferente. As empresas podem ser demandadas ou não, ou ser fortemente induzidas por seus clientes, dependendo de suas características, de sua percepção e posicionamento diante do mercado, e de sua especialidade de projeto.

No que se refere às demandas e às empresas de projeto, há fatores de influência externos mercado, tipo de cliente - e fatores de influência internos às empresas - identidade, estratégia de atuação e gestão. A gestão das empresas auxilia na definição de sua identidade e estratégia de atuação. No entanto, as empresas possuem uma série de deficiências em suas práticas gerenciais e de dificuldades na estruturação de sua gestão, o que compromete a consideração das demandas de mercado.

As empresas reconhecem que, em relação:

(a) ao desempenho de edifícios:

- há necessidade de atualização em relação à norma;

- necessidade de capacitação;

- necessidade de estudo da aplicação de softwares de medição de desempenho;

- há falta de documentação e ensaio de produtos brasileiros; $\mathrm{e}$
- projetos pouco especificados;

(b) à sustentabilidade ambiental de edifícios:

- há necessidade de reflexão sobre a demanda;

- necessidade de conhecer as diferentes

certificações ambientais;

- necessidade de conhecimento técnico sobre os requisitos ambientais;

- necessidade de conhecimento sobre o clima, as tecnologias existentes, a origem e o comportamento de materiais e componentes;

- necessidade de buscar fornecedores certificados e com produtos especificados;

- falta de informação técnica e produtos testados; e

(c) ao BIM:

- há necessidade de realização de um plano para sua implementação;

- necessidade de entender os vários aspectos que implicam sua implementação (SUCCAR, 2009;

OLATUNJI, 2011; KHOSROWSHAHI;

ARAYICI, 2012; GU; LONDON, 2010;

ARAYICI et al., 2011);

- necessidade de definir estratégias;

- necessidade de definir objetivos e metas;

necessidade de entrar em contato com os softwares BIM;

- há dificuldade no aproveitamento das oportunidades do mercado por parte das empresas, ou seja, em aproveitar a demanda existente;

- relação da implementação do BIM com a gestão da empresa (gestão de pessoas, financeira, do processo de projeto, etc.).

Apesar desse reconhecimento, parte das empresas insiste em uma postura passiva diante das demandas de mercado, tomando decisões de acordo com o momento. Esse comportamento é bastante prejudicial, uma vez que elas estão inseridas em um ambiente de incertezas. Recomenda-se que todas as empresas trabalhem seu planejamento estratégico, tendo o cuidado de definir seus objetivos e desdobrá-los em metas, ações e indicadores, permitindo a tomada de decisão fundamentada. Esse planejamento deve contemplar os módulos de gestão e as necessidades da empresa. Recomenda-se que as empresas definam sua atuação, considerando seus pontos fortes e fracos, ameaças e oportunidades (ZHAO et al., 2012; HOUBEN; LENIE; VANHOOF, 1999). Quanto às demandas de mercado especificamente, recomenda-se que as empresas analisem se estão preparadas para atender ao mercado - diagnóstico sobre sua situação atual - e verifiquem a 
necessidade de alteração de seus processos, de capacitação, treinamento interno e equipamentos, a possibilidade de parcerias com os clientes e de participação de entidades de classe ou grupos de empresas para discuti-las.

Como trabalhos futuros, sugere-se a proposição de diretrizes para a inserção de requisitos de desempenho no processo de projeto de edificações, assim como requisitos ambientais e BIM. Desse modo, propostas para a reformulação do processo de projeto são necessárias para permitir o atendimento aos requisitos e o trabalho com BIM.

\section{Referências}

ARAYICI, Y. et al. Technology Adoption in the BIM Implementation for Lean Architectural Practice. Automation in Construction, v. 20, n. 2, p. 189-195, mar. 2011.

\section{ASSOCIAÇÃO BRASILEIRA DE NORMAS} TÉCNICAS. NBR 15575: edificações habitacionais: desempenho. Rio de Janeiro, 2013.

AZHAR, S. et al. Building Information Modeling for Sustainable Design and LEED® Rating Analysis. Automation in Construction, v. 20, n. 2, p. 217-224, mar. 2011.

BYNUM, P.; ISSA, R. R. A.; OLBINA, S. Building Information Modeling in Support of Sustainable Design and Construction. Journal of Construction Engineering and Management, v. 139, n. 1, p. 24-34, jan. 2013.

CÂMARA BRASILEIRA DA INDÚSTRIA DA CONSTRUÇÃO. Desempenho de Edificações

Habitacionais: guia orientativo para atendimento à norma ABNT NBR 15575/2013. Fortaleza: Gadioli Cipolla Comunicação, 2013.

DE PAULA, N.; MELHADO, S. B. Effects of the Demand of Environmental Sustainability on the Building Design Stage. In: INTERNATIONAL CONFERENCE ON SMART AND SUSTAINABLE BUILT ENVIRONMENTS, 4., São Paulo, 2012. Anais... São Paulo: UNICAMP/UFES, 2012.

EASTMAN, C.; TEICHOLZ, P.; SACKS, R.; LISTON, K. BIM Handbook: a guide to building information modeling for owners, managers, designers, engineers, and contractors. New Jersey: John Wiley \& Sons, 2008.

FERRIES, B. L'Essentiel Maquette Numerique du Batiment BIM - IFC. 2009. Disponível em: <http://www.laurenti.com/publis/bimsbook.pdf>. Acesso em: 12 abr. 2013.
GU, N.; LONDON, K. Understanding and Facilitating BIM Adoption in the AEC Industry. Automation in Construction, v. 19, n. 8, p. 988999, dec. 2010.

HOUBEN, G.; LENIE, K.; VANHOOF, K. A Knowledge-Based SWOT-Analysis System as an Instrument for Strategic Planning in Small and Medium Sized Enterprises. Decision Support Systems, v. 26, n. 2, p. 125-135, ago. 1999.

KHOSROWSHAHI, F.; ARAYICI, Y. Roadmap For Implementation of BIM in the UK Construction Industry. Engineering, Construction and Architectural Management, v. 19, n. 6, p.610-635, 2012.

MELHADO, S. B. Gestão de Projetos Complexos e as Novas Demandas. In: SALGADO, M. S. et al. Projetos Complexos e seus Impactos na Cidade e na Paisagem. Rio de Janeiro:

UFRJ/FAU/PROARQ; ANTAC, 2012.

MELHADO, S. B.; CAMBIAGHI, H. Programa Setorial da Qualidade e Referencial Normativo para Qualificação de Empresas de Projeto. São Paulo: AsBEA/PCC USP, 2006. v. 5.

NOVASKI, M. A. M. et al. Estruturação de Um Novo Serviço em Empresa Projetista. In: ENCONTRO NACIONAL DE TECNOLOGIA DO AMBIENTE CONSTRUÍDO, 14., Juiz de Fora, 2012. Anais... Juiz de Fora: UFJF, 2012.

OLATUNJI, O. A. Modelling the Costs of Corporate Implementation of Building Information Modelling. Journal of Financial Management of Property and Construction, v. 16, n. 3, p. 211231, 2011.

OLIVEIRA, O. J. Modelo de Gestão Para Pequenas Empresas de Projeto de Edifícios.262 f. São Paulo, 2005. Tese (Doutorado em Engenharia de Construção Civil e Urbana) Escola Politécnica, Universidade de São Paulo, São Paulo, 2005.

OLIVEIRA, L. A.; MITIDIERI FILHO, C. V. O Projeto de Edifícios Habitacionais Considerando a Norma Brasileira de Desempenho: análise aplicada para as vedações verticais. Gestão e Tecnologia de Projetos, v. 7, n. 1, p. 90-100, maio 2012.

PARK, J. et al. Building Information Modelling Based Energy Performance Assessment System: an assessment of the Energy Performance Index in Korea. Construction Innovation: Information, Process, Management, v. 12, n. 3, p. 335-354, 2012. 
REKOLA, M.; MÄKELÄINEN, T.; HÄKKINEN, $\mathrm{T}$. The Role of Design Management in the Sustainable Building Process. Architectural Engineering and Design Management, v. 8, n. 2, p. 78-89, 2012.

ROYAL INSTITUTE OF BRITISH ARCHITECTS. RIBA Plan of Work 2013.

Disponível em:

<http://www.ribabookshops.com/plan-of-work>. Acesso em: 09 set. 2013.

SALGADO, M. S.; CHATELET, A.; FERNANDEZ, P. Produção de Edificações Sustentáveis: desafios e alternativas. Ambiente Construído, Porto Alegre, v. 12, n. 4, p. 81-99, out./dez. 2012.

SINDICATO DAS EMPRESAS DE COMPRA, VENDA, LOCAÇÃO E ADMINISTRAÇÃO DE IMÓVEIS RESIDENCIAIS E COMERCIAIS DE SÃO PAULO. Manuais de Escopo Para Contratação de Projetos e Serviços Para a Indústria Imobiliária. Disponível em: <http://www.manuaisdeescopo.com.br/>. Acesso em: 9 set. 2013.

SOUZA, F. R. Implementação de Modelo de Gestão para Empresas de Projeto. 202 f. São Paulo, 2009. Dissertação (Mestrado em Engenharia de Construção Civil) - Escola Politécnica, Universidade de São Paulo, São Paulo, 2009.
SOUZA, F. R. et al. O Programa de Desenvolvimento Gerencial para Empresas de Projeto. In: CONFERÊNCIA INTERNACIONAL DA LARES, 11., São Paulo, 2011. Anais... São Paulo: LARES, 2011.

SUCCAR, B. Building Information Modelling Framework: a research and delivery foundation for industry stakeholders. Automation in Construction, v. 18, n. 3, p. 357-375, maio 2009.

THIOLLENT, M. Metodologia da PesquisaAção. 13. ed. São Paulo: Cortez, 2004.

TRINIUS, W.; SJÖSTRÖM, C. Service Life Planning and Performance Requirements.

Building Research and Information, v. 33, n. 2, p. 173-181, mar. 2005.

ZHAO, Z. Y. et al. Foreign Architectural and Engineering Design Firms' Competitiveness and Strategies in China: a diamond model study.

Habitat International, v. 36, n. 3, p. 362-370, jul. 2012.

\section{Agradecimentos}

Os autores agradecem às empresas participantes do trabalho de pesquisa e à Capes, pela bolsa de pesquisa concedida a uma das autoras.

Nathália de Paula

Departamento de Engenharia de Construção Civil, Escola Politécnica | Universidade de São Paulo | Av. Prof. Almeida Prado, Trav. 2, n. 83, Cidade Universitária | São Paulo - SP - Brasil | CEP 05.508-900 | Tel. (11) 3091-5234 | E-mail: nathaliapaula@yahoo.com.br

\section{Mônica Emiko Uechi}

Departamento de Engenharia de Construção Civil, Escola Politécnica | Universidade de São Paulo | E-mail: monicaemiko@yahoo.com.br

Silvio Burrattino Melhado

Departamento de Engenharia de Construção Civil, Escola Politécnica | Universidade de São Paulo | E-mail: silvio.melhado@poli.usp.br

Revista Ambiente Construído

Associação Nacional de Tecnologia do Ambiente Construído

Av. Osvaldo Aranha, $99-3^{\circ}$ andar, Centro

Porto Alegre - RS - Brasil CEP 90035-190

Telefone: +55 (51) 3308-4084

Fax: +55 (51) 3308-4054

www.seer.ufrgs.br/ambienteconstruido

E-mail: ambienteconstruido@ufrgs.br 